ANAIS DA XVII SEMANA DE ENFERMAGEM DA UESPI,2019;14$\underline{74}$
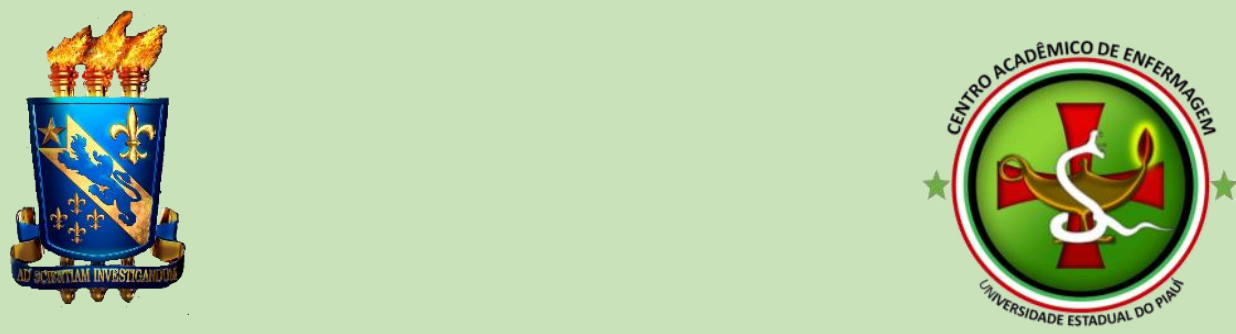

\title{
ANAIS DA XVII SEMANA DE ENFERMAGEM DA UESPI
}

\section{APOIO:}

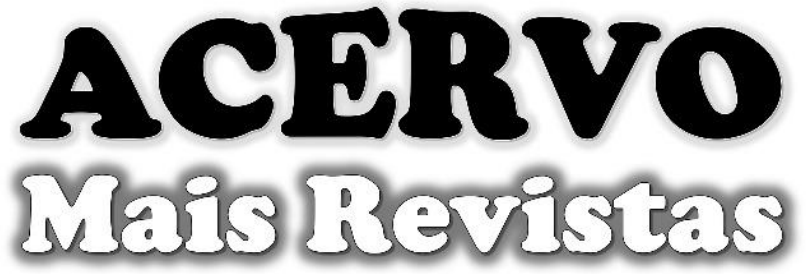

As publicações mais rápidas do país!

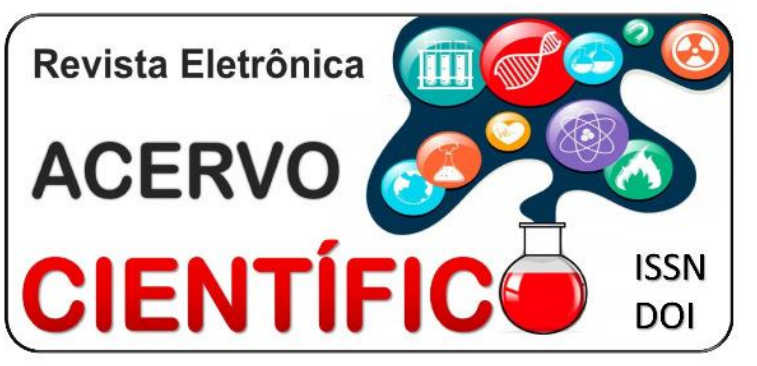




\section{ANAIS DA XVII SEMANA DE ENFERMAGEM DA UESPI}

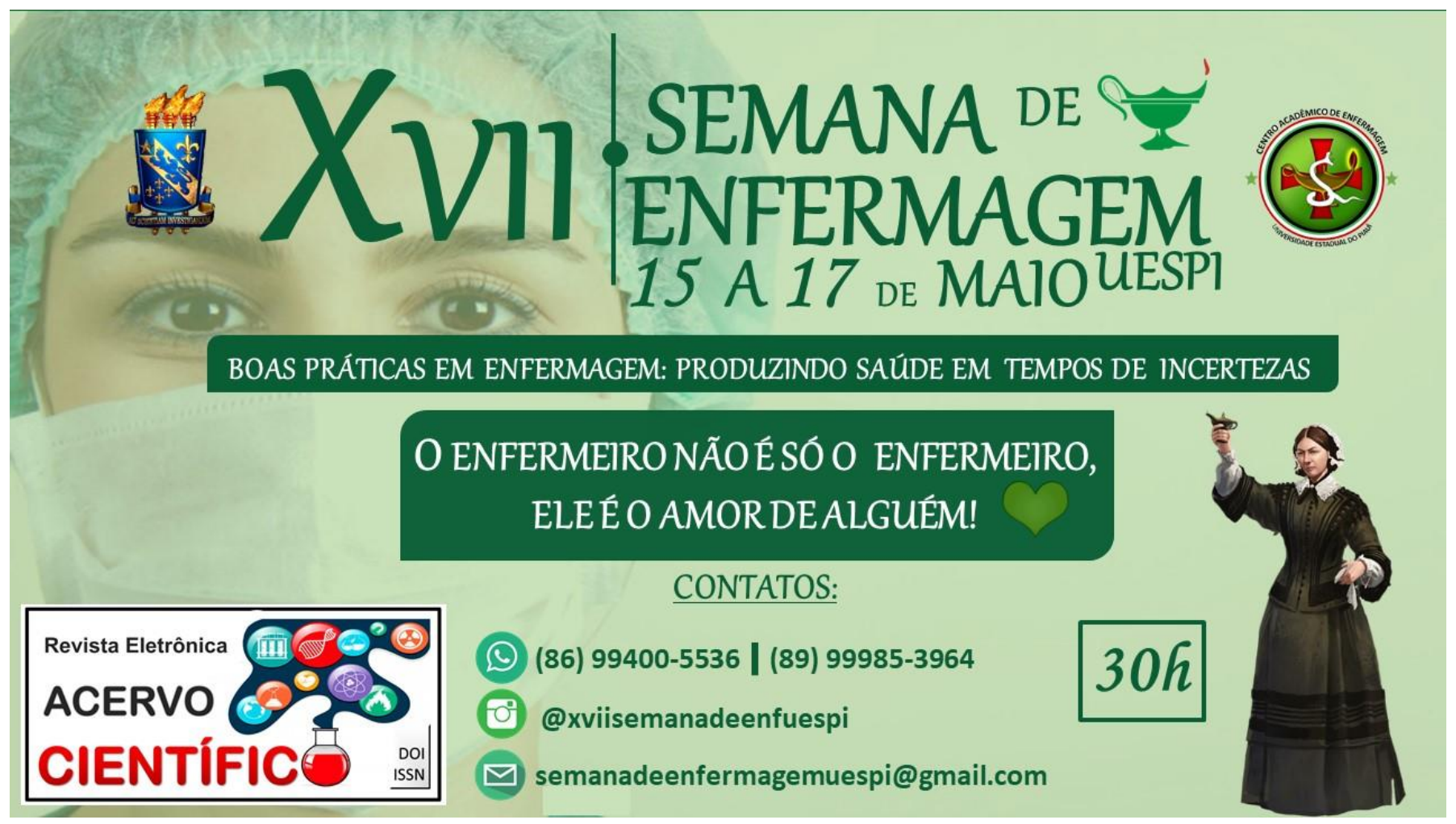

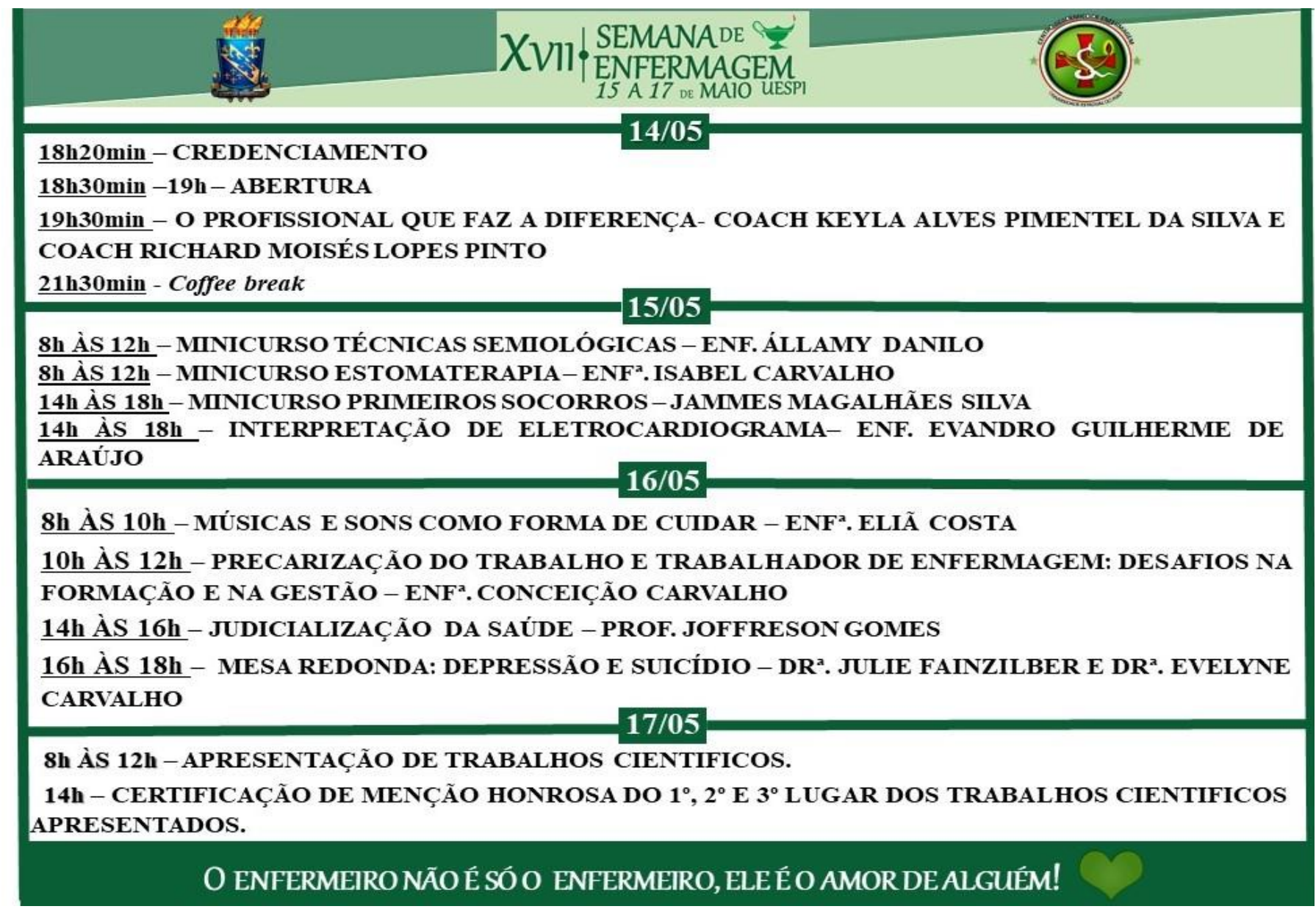




\title{
ANAIS DA XVII SEMANA DE ENFERMAGEM DA UESPI
}

\author{
ORGANIZACÃO: \\ COORDENAÇÃO GERAL \\ Mohema Duarte de Oliveira \\ COORDENAÇÃO CIENTIFICA \\ Andréa Pereira da Silva \\ COORDENAÇÃO DE INFRAESTRUTURA \\ Natacha Kalu dos Santos Bernardes Gonçalves \\ CENTRO ACADÊMICO DE ENFERMAGEM - CAEnfer \\ Juan Victor da Silva \\ Lorena Valter de Sousa \\ Alessandra Beltrami Oliveira \\ João Victor de Sousa Lima \\ Kamilla Rocha Arrais \\ Maria de Jesus Estevam da Silva \\ Mateus de Sousa \\ Misael Magalhães Santos Alves \\ Rhayane Ellen Carvalho Feitosa

\section{COLABORADORES:} \\ DIREÇÃO DO CAMPUS DR. ․ JOSEFINA DEMES - UESPI \\ Ariete Ferreira Costa Bento \\ Adail Pereira Carvalho Júnior \\ PROFESSORES(AS) DO CAMPUS DR.- JOSEFINA DEMES - UESPI \\ Adelzira Ferreira Cardoso \\ Államy Danilo Moura \\ Evelyne Ellene Alves de Carvalho \\ Jayra Adriana da Silva Sousa \\ Maria Luzinete Rodrigues da Silva \\ Maria Madalena Gomes Pereira Máximo \\ Robinson Pereira da Silva
}




\section{ANAIS DA XVII SEMANA DE ENFERMAGEM DA UESPI}

\section{MONITORES:}

\section{COMISSÃO GERAL}

Ana Christina de Sousa Baldoino

Filomena Maria Melo da Silva Nunes

lanny Soares de Carvalho

Jhussara Silva Alves

Joana Beatriz de Lima Silva

Raiane Araujo Brito

Rômulo Egídio Rodrigues do Nascimento

Tássia Iris de Carvalho Costa

Thalissa Saraiva Leitão

\section{COMISSÃO CIENTÍFICA}

Alessandra dos Santos de Araújo Rodrigues

Arturgesina Martins Vasconcelos Lima

Daiane Magalhães Silva

Kellícia Rocha Arrais

Suzana Honória de Sousa

\section{COMISSÃO DE INFRAESTRUTURA}

Ana Maria da Costa Oliveira

Debora Marques da Silva

lago de Sousa Fernandes

Izabela Sousa Martins

Lais Alves de Sousa

Luan Wesley Marques Máximo

Maiara Soares Gomes da Silva

Susidárlem Batista da Silva 


\section{COMISSÃO DE AVALIACÃO DOS TRABALHOS CIENTÍFICOS:}

\section{MODALIDADE COMUNICAÇÃO ORAL:}

Ludiane Rodrigues Dias Silva

Maria Luzinete Rodrigues da Silva

Pedro Emanoel de Sousa Ferreira MODALIDADE PÔSTER:

Adelzira Rodrigues Cardoso

Camila Cardoso de Araújo Costa

Cleidiane Vieira Soares Cabral 


\section{APRESENTAÇÃO}

A Semana da Enfermagem é um período especial, revestido de muita importância para todos os docentes, alunos e profissionais de enfermagem, como oportunidade para a promoção da relevância das ações de enfermagem para o pleno atendimento às demandas de saúde em resposta às necessidades básicas afetadas da comunidade. Hoje, a Semana de enfermagem da UESPI, campus DR. ․ Josefina Demes, encontra-se em sua decima sétima edição, sempre visando aprimorar os conhecimentos sistematizados de estudantes e profissionais da área de Enfermagem, tendo como objetivo tentar compreender a situação da qualidade do cuidado de enfermagem em tempos tão difíceis para a categoria.

Com o tema "Boas práticas em enfermagem: produzindo saúde em tempos de incertezas", vivências e experiências dos profissionais foram ressaltadas por meio de palestras, minicursos e mesas redondas, atribuindo sentidos e significados da prática dos profissionais e dos acadêmicos, que foram aperfeiçoadas ao longo do tempo, desse modo tal evento contribuiu significativamente para a formação dos estudantes enquanto futuros profissionais de Enfermagem, ensinando ao profissional de enfermagem que o cuidado é amplo e que o próprio enfermeiro também é o amor de alguém. Este caderno possui todos os trabalhos aprovados, na modalidade comunicação oral e pôster, para apresentação da XVII Semana de Enfermagem da UESPI.

Floriano - Piauí, 17 de Maio de 2019

Juan Victor Da Silva

Presidente do Centro Acadêmico de Enfermagem 


\section{ANAIS DA XVII SEMANA DE ENFERMAGEM DA UESPI}

SUMÁRIO DE TRABALHOS DA MODALIDADE COMUNICAÇÃO ORAL

\begin{tabular}{|c|c|c|c|}
\hline $\mathbf{N}^{\mathbf{o}}$ & TÍTULO & AUTORES & PÁGINA \\
\hline 01 & $\begin{array}{l}\text { A Capacitação do Enfermeiro } \\
\text { na Prevenção do Suicídio: } \\
\text { Revisão de Literatura }\end{array}$ & $\begin{array}{l}\text { Misael Magalhães Santos Alves, } \\
\text { Kellícia Rocha Arrais, Kamilla } \\
\text { Rocha Arrais, Matheus de Sousa, } \\
\text { Antônio Gabriel dos Santos } \\
\text { Castro, Evelyne Ellene Alves de } \\
\text { Carvalho. }\end{array}$ & 14 \\
\hline 02 & $\begin{array}{c}\text { Contribuições da Enfermagem } \\
\text { ao Paciente que se } \\
\text { Automutila }\end{array}$ & $\begin{array}{l}\text { João Victor de Sousa Lima, Laís } \\
\text { Alves de Sousa, Ana Maria da } \\
\text { Costa Oliveira, Alessandra } \\
\text { Beltrami Oliveira, Suzana } \\
\text { Honória de Sousa, Evelyne } \\
\text { Ellene Alves de Carvalho. }\end{array}$ & 17 \\
\hline 03 & $\begin{array}{l}\text { Do Estresse Ocupacional } \\
\text { ao Surgimento da } \\
\text { Síndrome de Burnout em } \\
\text { Profissionais da } \\
\text { Enfermagem: Uma } \\
\text { Revisão Integrativa } \\
\end{array}$ & $\begin{array}{l}\text { Hernandes Flanklin Carvalho } \\
\text { Oliveira, Magdiel da Costa } \\
\text { Silva, Suzana Honória de Sousa, } \\
\text { Raiane Araújo Brito, Jhussara } \\
\text { Silva Alves, Evelyne Ellene } \\
\text { Alves de Carvalho. }\end{array}$ & 20 \\
\hline 04 & $\begin{array}{l}\text { A Depressão Pós-Parto e os } \\
\text { Principais Fatores Associados } \\
\text { ao seu Desenvolvimento }\end{array}$ & $\begin{array}{l}\text { Ana Maria da Costa Oliveira, } \\
\text { Alessandra Beltrami Oliveira, } \\
\text { Laís Alves de Sousa, João } \\
\text { Victor de Sousa Lima, Suzana } \\
\text { Honória de Sousa, Evelyne } \\
\text { Ellene Alves de Carvalho. }\end{array}$ & 23 \\
\hline 05 & $\begin{array}{c}\text { Análise Microbiana dos } \\
\text { Alimentos Oferecidos em } \\
\text { Escolas Públicas da Cidade de } \\
\text { Floriano-PI }\end{array}$ & $\begin{array}{l}\text { Matheus Lima dos Reis Sousa, } \\
\text { Bianca Leite Carnib de Sousa, } \\
\text { Pedro Samuel Rodrigues Rego, } \\
\text { Yanez André Gomes Santana. }\end{array}$ & 26 \\
\hline
\end{tabular}




\section{ANAIS DA XVII SEMANA DE ENFERMAGEM DA UESPI}

\section{SUMÁRIO DE TRABALHOS DA MODALIDADE COMUNICAÇÃO ORAL}

\begin{tabular}{|c|c|c|c|}
\hline 06 & $\begin{array}{c}\text { Assistência de Enfermagem } \\
\text { ao Paciente com Derrame } \\
\text { Pleural: Relato de } \\
\text { Experiência }\end{array}$ & $\frac{\text { Kellícia Rocha Arrais, Julyanne }}{\text { dos Santos Nolêto. }}$ & 29 \\
\hline 07 & $\begin{array}{c}\text { Desenvolvimento e Análise } \\
\text { Físico } \\
\text { - Químico da Planta } \\
\text { Citronela como Repelente } \\
\text { Veiculado em Gel Creme }\end{array}$ & Aludy Karina de Carvalho Costa. & 32 \\
\hline 08 & $\begin{array}{l}\text { Dinâmica Grupal Como } \\
\text { Estratégia Terapêutica em Um } \\
\text { Centro de Atenção Psicossocial }\end{array}$ & $\begin{array}{l}\text { Priscilla Souza Silva, Ananda } \\
\text { Carolina Barbosa da Silva, Ana } \\
\text { Caroliny de Barros Soares Lima, } \\
\text { Nanielle Silva Barbosa, Kauan } \\
\text { Gustavo de Carvalho, Lorena } \\
\text { Uchoa Portela Veloso. }\end{array}$ & 35 \\
\hline 09 & $\begin{array}{c}\text { Prevalência e Fatores } \\
\text { Relacionados ao } \\
\text { Comportamento Suicida Entre } \\
\text { Minorias Sexuais }\end{array}$ & $\begin{array}{l}\text { Priscilla Souza Silva, Ananda } \\
\text { Carolina Barbosa da Silva, Ana } \\
\text { Caroliny de Barros Soares Lima, } \\
\text { Nanielle Silva Barbosa, Kauan } \\
\text { Gustavo de Carvalho, Lorena } \\
\text { Uchoa Portela Veloso. }\end{array}$ & 38 \\
\hline 10 & $\begin{array}{c}\text { Fatores Associados a Não } \\
\text { Adesão ao Exame } \\
\text { Citopatológico }\end{array}$ & $\begin{array}{l}\text { Daiane Magalhães Silva, } \\
\text { Alessandra dos Santos de Araújo } \\
\text { Rodrigues, Ianny Soares de } \\
\text { Carvalho, Joana Beatriz de Lima } \\
\text { Silva, Maria Luzinete Rodrigues } \\
\text { da Silva. }\end{array}$ & 41 \\
\hline 11 & $\begin{array}{l}\text { Relutância do Homem na } \\
\text { Assistência Primária a } \\
\text { Saúde: Revisão Integrativa }\end{array}$ & $\begin{array}{l}\text { Raiane Araujo Brito, Hernandes } \\
\text { Flanklin Carvalho Oliveira, } \\
\text { Jhussara Silva Alves, Rayssa do } \\
\text { Nascimento Sousa, Államy } \\
\text { Danilo Moura e Silva. }\end{array}$ & 44 \\
\hline
\end{tabular}




\section{ANAIS DA XVII SEMANA DE ENFERMAGEM DA UESPI}

\section{SUMÁRIO DE TRABALHOS DA MODALIDADE PÔSTER}

\begin{tabular}{|c|c|c|c|}
\hline $\mathbf{N}^{\mathbf{0}}$ & TÍTULO & AUTORES & PÁGINA \\
\hline 01 & $\begin{array}{l}\text { A Importância da Anamnese } \\
\text { e Exame Físico Realizado } \\
\text { pela Enfermagem a } \\
\text { Pacientes Hospitalizados: } \\
\text { Relato de Experiência }\end{array}$ & $\begin{array}{l}\text { Sueli de Sousa Estrela } \\
\text { Araújo, Suzana Honória } \\
\text { de Sousa, Arturgesina } \\
\text { Martins Vasconcelos } \\
\text { Lima, Maraisa Piauilino } \\
\text { de Lima, Elusiany Sousa } \\
\text { Silva, Maria Luzinete } \\
\text { Rodrigues da Silva. }\end{array}$ & 48 \\
\hline 02 & $\begin{array}{l}\text { A Perspectiva Prática e a } \\
\text { Liderança em } \\
\text { Enfermagem: Revisão de } \\
\text { Literatura }\end{array}$ & $\begin{array}{lr}\text { Maraisa } & \text { Piauilino de } \\
\text { Lima, Suzana Honória de } \\
\text { Sousa, } \\
\text { Martins Arturgesina } \\
\text { Lima, Sueli de Sousa } \\
\text { Estrela Araújo, Elusiany } \\
\text { Sousa Silva, Maria } \\
\text { Luzinete Rodrigues da } \\
\text { Silva. }\end{array}$ & 50 \\
\hline 03 & $\begin{array}{l}\text { Assistência de Enfermagem } \\
\text { ao Paciente no Pós- } \\
\text { Operatório de } \\
\text { Prostatectomia: Relato de } \\
\text { Experiência }\end{array}$ & $\begin{array}{lr}\text { Arturgesina } & \text { Martins } \\
\text { Vasconcelos } & \text { Lima, } \\
\text { Suzana Honória de Sousa, } & \\
\text { Conceição de Maria } \\
\text { Vasconcelos Alves, Sueli } \\
\text { de Sousa Estrela Araújo, } \\
\text { Elusiany Sousa da Silva, } \\
\text { Maria Luzinete Rodrigues } \\
\text { da Silva. }\end{array}$ & 52 \\
\hline 04 & $\begin{array}{l}\text { Aspectos Epidemiológicos } \\
\text { da Sífilis Congênita no } \\
\text { Estado do } \\
\text { Piauí }\end{array}$ & $\begin{array}{l}\text { Kellícia Rocha Arrais, } \\
\text { Jefferson Abraão Caetano } \\
\text { Lira, Rutielle Ferreira } \\
\text { Silva, Julyanne dos Santos } \\
\text { Nolêto }\end{array}$ & 54 \\
\hline
\end{tabular}




\section{ANAIS DA XVII SEMANA DE ENFERMAGEM DA UESPI}

\section{SUMÁRIO DE TRABALHOS DA MODALIDADE PÔSTER}

\begin{tabular}{|c|c|c|c|}
\hline 05 & $\begin{array}{l}\text { Assistência de Enfermagem } \\
\text { à Mulher no Puerpério }\end{array}$ & $\begin{array}{l}\text { Alice Vitória Reis Evelyn } \\
\text { da Silva, Laise Pereira da } \\
\text { Silva Brito, Mayara } \\
\text { Rodrigues dos Santos, } \\
\text { Priscilla Souza Silva, } \\
\text { Adriana da Silva Barros } \\
\text { Andrade. }\end{array}$ & 56 \\
\hline 06 & $\begin{array}{c}\text { Conhecimento das Mães de } \\
\text { Recém Nascidos Submetidos } \\
\text { a Fototerapia: Revisão De } \\
\text { Literatura }\end{array}$ & $\begin{array}{l}\text { Elusiany Sousa da Silva, } \\
\text { Arturgesina Martins } \\
\text { Vasconcelos Lima, } \\
\text { Maraisa Piauilino de } \\
\text { Lima, Suzana Honória de } \\
\text { Sousa, Sueli de Sousa } \\
\text { Estrela Araújo, Adriana da } \\
\text { Silva Barros Andrade. }\end{array}$ & 58 \\
\hline 07 & $\begin{array}{l}\text { Educação em Saúde Sobre } \\
\text { Aleitamento Materno em } \\
\text { Uma Maternidade } \\
\text { Referência do Piauí: Um } \\
\text { Relato de Experiência }\end{array}$ & $\begin{array}{l}\text { Ana Christina de Sousa } \\
\text { Baldoino, Nanielle Silva } \\
\text { Barbosa, Kauan Gustavo } \\
\text { de Carvalho, Ana Caroliny } \\
\text { de Barros Lima, Priscilla } \\
\text { Souza Silva, Ananda } \\
\text { Carolina Barbosa } \\
\text { da Silva. }\end{array}$ & 60 \\
\hline 08 & $\begin{array}{l}\text { Efetividade da Papaína no } \\
\text { Tratamento de Feridas: } \\
\text { Revisão Integrativa }\end{array}$ & $\begin{array}{lrr}\text { Kamilla } & \text { Rocha } & \text { Arrais, } \\
\text { Kellícia } & \text { Rocha Arrais, } \\
\text { Karolay } & \text { Sousa } & \text { Silva, } \\
\text { Andréa Pereira da Silva. }\end{array}$ & 62 \\
\hline 09 & $\begin{array}{c}\text { Fatores de Risco Associados } \\
\text { à Síndrome de Hellp na } \\
\text { Gestação: Uma Revisão } \\
\text { Integrativa }\end{array}$ & $\begin{array}{l}\text { Iara Maria Lima da Silva, } \\
\text { Sandy Soares Sousa, } \\
\text { Yanneck Barbosa Silva, } \\
\text { Marianna Soares Cardoso, } \\
\text { Andréa Pereira da Silva. }\end{array}$ & 64 \\
\hline 10 & $\begin{array}{c}\text { Motivos da Procura ao } \\
\text { Centro de Testagem e } \\
\text { Aconselhamento do } \\
\text { Município de Floriano - PI }\end{array}$ & $\begin{array}{l}\text { Laise Pereira da Silva } \\
\underline{\text { Brito, Fabiano de Araujo }} \\
\text { Silva, Maria Luzinete } \\
\text { Rodrigues da Silva, } \\
\text { Mayara Rodrigues dos } \\
\text { Santos, Wesley Romário } \\
\text { Dias Martins, Andréa } \\
\text { Pereira da Silva. }\end{array}$ & 66 \\
\hline 11 & $\begin{array}{c}\text { Orientação Sexual e } \\
\text { Vulnerabilidade ao Vírus da } \\
\text { Imunodeficiência Humana }\end{array}$ & $\begin{array}{l}\text { Laise Pereira da Silva } \\
\underline{\text { Brito, Fabiano de Araujo }} \\
\text { Silva, Maria Luzinete } \\
\text { Rodrigues da Silva, } \\
\text { Mayara Rodrigues dos } \\
\text { Santos, Wesley Romário } \\
\text { Dias Martins, Andréa } \\
\text { Pereira da Silva. }\end{array}$ & 68 \\
\hline
\end{tabular}




\begin{tabular}{|c|c|c|c|}
\hline 12 & $\begin{array}{c}\text { Enfermagem Frente aos } \\
\text { Efeitos Adversos da } \\
\text { Quimioterapia: Uma } \\
\text { Revisão Integrativa da } \\
\text { Literatura }\end{array}$ & $\begin{array}{l}\text { Luan Wesley Marques } \\
\text { Máximo, Priscilla Souza } \\
\text { Silva, Ananda Carolina } \\
\text { Barbosa da Silva, Ana } \\
\text { Caroliny de Barros Lima, } \\
\text { Kauan Gustavo de } \\
\text { Carvalho, Nanielle Silva } \\
\text { Barbosa. }\end{array}$ & 70 \\
\hline 13 & $\begin{array}{c}\text { Persistência do Estigma } \\
\text { Social Frente ao Acometido } \\
\text { pela Hanseníase }\end{array}$ & $\begin{array}{l}\text { Matheus de Sousa, } \\
\text { Antonio Gabriel dos } \\
\text { Santos Castro, Misael } \\
\text { Magalhães Santos Alves, } \\
\text { Jhussara Silva Alves, } \\
\text { Államy Danilo Moura e } \\
\text { Silva. }\end{array}$ & 72 \\
\hline 14 & $\begin{array}{c}\text { Reflexão da Formação } \\
\text { Acadêmica no Cuidado } \\
\text { Humanizado em } \\
\text { Enfermagem: Revisão de } \\
\text { Literatura }\end{array}$ & $\begin{array}{l}\text { Sueli de } \\
\text { Araújo, }\end{array}$ & 74 \\
\hline
\end{tabular}




\section{ANAIS DA XVII SEMANA DE ENFERMAGEM DA UESPI}

\section{RESUMOS DA XVII SEMANA DE ENFERMAGEM DA UESPI}




\section{ANAIS DA XVII SEMANA DE ENFERMAGEM DA UESPI}

\section{RESUMOS MODALIDADE COMUNICAÇÃO ORAL}




\section{ANAIS DA XVII SEMANA DE ENFERMAGEM DA UESPI}

\section{A CAPACITAÇÃO DO ENFERMEIRO NA PREVENÇÃO DO SUICÍDIO: REVISÃO DE LITERATURA}

Misael Magalhães Santos Alves ${ }^{1}$, Kellícia Rocha Arrais ${ }^{2}$, Kamilla Rocha Arrais ${ }^{3}$, Matheus de Sousa ${ }^{4}$, Antônio Gabriel dos Santos

Castro $^{5}$, Evelyne Ellene Alves de Carvalho. E-mail: misaelmagalhaes73@gmail.com

Universidade Estadual do Piauí-UESPI, Floriano-PI, Brasil.

Eixo temático: Enfermagem no processo saúde-doença.

INTRODUÇÃO: Suicídio vem do latim sui que quer dizer de si mesmo, e de caederes, ação de matar. Foi um termo criado por Desfontaines em 1977, designando a busca por uma solução para o sofrimento que parece ser infindável. Figura como grave problema de saúde em nível mundial, com quase um milhão de pessoas se suicidando por ano e estimativa de seis pessoas do ambiente diretamente afetadas por cada morte. O impacto psicológico, social e econômico do suicídio na família e na comunidade é imensurável. Com base na tendência atual, estima-se que, em 2020, as mortes por suicídio alcançarão 1.53 milhões de pessoas no mundo, com número entre 10-20 vezes maior para casos de tentativas de suicídio. OBJETIVO: Analisar as evidências cientificas disponíveis acerca da capacitação do enfermeiro na prevenção do suicídio. MÉTODO: Trata-se de uma revisão de literatura, realizada nas bases de dados LILACS, BDENF e SciELO, utilizando como descritores, os termos: Capacitação, Enfermeiro e Suicídio. O levantamento abrangeu as publicações da enfermagem brasileira entre os anos 2012 e 2018, sendo identificadas dez referências que contemplaram a amostra do estudo. RESULTADOS E DISCUSSÃO: Alguns estudos apontam que quanto maior a formação profissional, especialmente a de enfermeiros, mais positivas serão as atitudes em relação ao comportamento suicida. A formação em saúde mental também favorece o desenvolvimento de atitudes positivas, principalmente na capacidade para lidar com o paciente, mas não garante a presença de atitude empática ou menos condenatória. Na atenção básica à saúde, o enfermeiro ocupa lugar central no atendimento aos pacientes, além de ser responsável pelo treinamento e educação continuada da equipe de enfermagem e dos agentes comunitários (MAGRINI, 2016). De forma geral os profissionais da saúde apresentam dificuldade em identificar e lidar com pacientes suicidas, inclusive os médicos e os enfermeiros. O despreparo dos profissionais no atendimento desses pacientes pode desencadear conflitos internos e mobilizar emoções de caráter negativo naqueles que os atendem, prejudicando a abordagem (SILVA, 2014). Entende-se que a falta de conhecimento por parte dos profissionais de enfermagem sobre problemas psicológicos ou pacientes com comportamento suicida gera um atendimento de forma inadequada tendo em vista que o enfermeiro é o principal responsável pelo êxito da implementação do atendimento pré-hospitalar. É de suma importância que o enfermeiro esteja preparado para esse tipo de intercorrência tendo em vista o grande número de casos e atendimentos. O enfermeiro deve estar atento à qualidade do serviço que é prestado sabendo que quanto melhor for o atendimento melhor será a resposta e o prognóstico do paciente (SILVA, 2017). Outro aspecto importante a ser considerado no processo de capacitação dos profissionais 


\section{ANAIS DA XVII SEMANA DE ENFERMAGEM DA UESPI}

diz respeito ao estigma associado aos pacientes que exibem comportamento suicida (STORINO, 2018). Buriola et al. (2011) pontuam a importância da capacitação do enfermeiro para que possa ir além de suas rotinas assistenciais, estabelecer o cuidado humanizado e acolhimento eficaz aos indivíduos envolvidos nesse momento angustiante. O cuidado humanizado e a empatia dos profissionais são instrumentos primordiais na construção de vínculos com o paciente, edificados com confiança e respeito. O paciente necessita ser compreendido dentro do seu contexto para que possa sentir segurança para verbalizar sobre seus problemas e sofrimento. Evidenciou-se que atuação do enfermeiro ocorre nos múltiplos espaços de trabalho perante as pessoas em situação de suicídio nos quais o Serviço de Emergência, a Estratégia Saúde da Família, Hospital Psiquiátrico e o Centro de Atenção Psicossocial são seus campos de atuação, onde são aplicadas as intervenções às pessoas que prescindem de cuidados tão específicos (SANTOS, 2017).

CONCLUSÃO: Este estudo é uma contribuição para a saúde pública, alertando da necessidade de capacitar efetivamente os profissionais de enfermagem para que haja detecção precoce e tratamento adequado, pois é uma alternativa viável que pode resultar na diminuição dos coeficientes de mortalidade por suicídio. As capacitações podem ser uma importante via de conhecimento acerca do suicídio e práticas de cuidado às pessoas que tentaram tirar suas próprias vidas, tendendo, ainda, a proporcionar uma reflexão sobre o tema, que poderá facilitar a construção de atitudes ausentes de julgamento moral. Neste sentido, sugere-se a inclusão de uma disciplina optativa, acerca da temática, na grade curricular dos cursos de graduação em Enfermagem.

PALAVRAS-CHAVE: Capacitação, Enfermeiro, Suicídio.

\section{REFERÊNCIAS}

BURIOLA, Aline Aparecida et al. Assistência de enfermagem às famílias de indivíduos que tentaram suicídio. Escola Anna Nery. Rio de Janeiro, v. 15, $\mathrm{n}^{\circ}$ 4, dez. 2011. Disponível em: $<\mathrm{http} / / / \mathrm{www}$.scielo.br/scielo.php?script=sci_arttext\&pid=S141481452011000400008\&lng=en\&nrm=iso >. Acesso em: 25 de abr. 2019.

MAGRINI DF. Atitudes dos profissionais de enfermagem que atuam em emergências diante do comportamento suicida e fatores associados [dissertação]. Ribeirão Preto: Universidade de São Paulo, Escola de Enfermagem de Ribeirão Preto; 2016. Disponível em: http://revistacientifica.facmais.com.br/wp-content/uploads/2017/09/2. Acesso em: 25 de abr. 2019.

SANTOS RS, Albuquerque MCS de Brêda MZ et al. A atuação do enfermeiro com a pessoa em situação de suicídio: análise reflexiva / Nurses' actions towards suicide attempters: reflective analysis. Revista enfermagem UFPE online;11(2):742-748, fev. 2017. Disponível em: DOI: 10.5205/reuol.10263-915681-RV.1102201731. Acesso em: 25 de abr. 2019. 


\section{ANAIS DA XVII SEMANA DE ENFERMAGEM DA UESPI}

SILVA CAM, et al. Atuação do profissional enfermeiro no atendimento ao paciente por tentativa de suicídio. Revista Científica FacMais. Volume. IX, Número 2. julho. Ano 2017/2 Semestre. ISSN 22388427. Disponível em: http://revistacientifica.facmais.com.br/wp-content/uploads/2017/09/2.ATUA\%C3\%87\%C3\%83O-DO-PROFISSIONAL-ENFERMEIRO-NO-ATENDIMENTO-AO-

PACIENTE-POR-TENTATIVA-DE-SUIC\%C3\%8DDIO.pdf. Acesso em: 25 de abr. 2019.

SILVA LLT. Atitudes e percepções de estudantes e professores de enfermagem frente ao suicídio de adolescentes [tese]. Belo Horizonte: Faculdade de Medicina, Universidade Federal de Minas Gerais; 2014. Disponível em: http://www.bibliotecadigital.ufmg.br/dspace/bitstream/handle/1843/BUBD- 9VZJ4H/tese final.pdf?sequence=1. Acesso em: 25 de abr. 2019.

STORINO, Bárbara Diniz et al. Atitudes de profissionais da saúde em relação ao comportamento suicida. Cadernos saúde coletiva. Rio de Janeiro, v. 26, n. 4, p. 369-377, Dec. 2018. Disponível em: http://dx.doi.org/10.1590/1414-462x201800040191. Acesso em: 25 de abr. 2019. 


\section{ANAIS DA XVII SEMANA DE ENFERMAGEM DA UESPI}

\section{CONTRIBUIÇÕES DA ENFERMAGEM AO PACIENTE QUE SE AUTOMUTILA}

$\underline{\text { João Victor de Sousa Lima }}^{1}$, Laís Alves de Sousa ${ }^{1}$, Ana Maria da Costa Oliveira ${ }^{1}$, Alessandra Beltrami Oliveira ${ }^{1}$, Suzana Honória de Sousa ${ }^{1}$, Evelyne Ellene Alves de Carvalho ${ }^{1}$. E-mail: joaovictorlima087@gmail.com

${ }^{1}$ Universidade Estadual do Piauí - UESPI, Floriano-PI, Brasil.

Área temática: Enfermagem no Processo Saúde/Doença

INTRODUÇÃO: Automutilação é a prática de danos ao próprio corpo de maneira proposital, com intuito de obter alívio de um estado de sentimento ou cognição negativos, resolver uma dificuldade interpessoal e induzir um estado de sentimento positivo. Porém, mesmo não estando necessariamente ligada ao suicídio, a automutilação surge como um fator de risco muito frequente em pessoas que cometem suicídio (ARATANGY, 2017; PEIXOTO, 2017). De acordo com estudos, 20\% dos jovens se automutilam, e o surgimento e prevalência dessa prática está relacionada com alguns fatores, tais como: traumas, pessimismo, insegurança, ansiedade, depressão e outros aspectos psicológicos (ARATANGY, 2017; LOURENÇO, 2008). O cuidado com pacientes que se automutilam faz parte da clínica de enfermagem e, de acordo com a Lei $\mathrm{N}^{\mathrm{o}} 13.819$, de 2019, todo caso de violência autoprovocada deve ser notificada pela equipe de saúde. OBJETIVO: O objetivo desta pesquisa é avaliar a assistência de enfermagem no diagnóstico e tratamento dos pacientes que se automutilam. MÉTODOS: O trabalho em questão é uma revisão de literatura integrativa, de cunho qualitativo, que tem como objetivo discorrer a respeito da clínica de enfermagem, que inclui diagnóstico e tratamento, em pacientes que se automutilam, buscando enumerar táticas e instrumentos de uso simples para a melhoria da assistência de enfermagem nesses casos. Para tanto, procedeu-se com a seguinte cronologia: delimitação do tema, pesquisas de trabalhos científicos, seleção de artigos e síntese dos mesmos. A coleta de dados foi realizada no período de março a maio de 2019. Os descritores foram: automutilação, perfil epidemiológico e diagnóstico de enfermagem. Os critérios de inclusão foram: obras publicadas de 2008 a 2019, escritas em português, que tratassem do tema "contribuições de enfermagem ao paciente que se automutila". E os critérios de exclusão foram: trabalhos publicados em língua estrangeira e em anos anteriores a 2008. RESULTADOS E DISCUSSÃO: Diante da revisão de literatura realizada, os aspectos relacionados a atuação do Enfermeiro ao paciente que se automutila, assim como o diagnóstico, a intervenção e o tratamento, precisam ser mais discutidos, visto que de início já é possível observar as escassez de trabalhos desenvolvidos acerca da temática, assim como há, com base nos estudos, pouco conhecimento do Enfermeiro com relação ao evento descrito, tanto na acolhida, quanto nas orientações e tratamento. De acordo com estudos, a maioria dos pacientes automutilatórios que procuram tratamento, possuem alguma comorbidade que influencia nesse processo, dentre elas, em ordem decrescente, pode-se citar: depressão (92,5\%); transtorno obsessivo-compulsivo (57,5\%), transtorno de estresse pós-traumático $(40 \%)$ e transtorno de ansiedade (37,5\%) (ARATANGY, 2017). As demais comorbidades têm poucos 


\section{ANAIS DA XVII SEMANA DE ENFERMAGEM DA UESPI}

casos relatados. Pesquisas apontam que o ato de se automutilar começa na adolescência, entre os 13 e 14 anos, com a possibilidade de persistir por 10 a 15 anos. Os comportamentos mais frequentes são cortes em locais de fácil acesso, feitos com estilete, gilete ou tesoura, além de bater em si mesmo ou queimar-se. Os motivos comumente frequentes para essas ações são a busca por aliviar um sofrimento psíquico, de um sentimento ruim, indesejável, que pode ser camuflado pela automutilação (ARATANGY, 2017; LOURENÇO, 2008). O Enfermeiro enfrenta o grande desafio de lidar com as dificuldades encontradas ao prestar cuidados na gerência dos comportamentos da automutilação, já que tendem a ser o grupo profissional primário, no que diz respeito ao atendimento às pessoas que se automutilam, ao nível dos serviços de saúde. Para González (2017), Diniz (2017); Nanda (2015) apud Peixoto (2017), o cuidado com pacientes que praticam automutilação faz parte da clínica de enfermagem. A avaliação desses pacientes é feita através da Sistematização da Assistência em Enfermagem (SAE) aparecendo como Diagnóstico de Enfermagem (DE) em manuais de classificação específicos da profissão. Mas para que isso aconteça, diante dos estudos, foi observado para que o profissional deve, inicialmente, ter conhecimento sobre a automutilação. Diante disso, deve transparecer curiosidade, com respeito, e não apenas com interesse em se livrar do problema, mas entendê-lo melhor. É essencial que sejam feitas perguntas acolhedoras, para que o paciente se sinta ambientado e confortável para falar a respeito do problema. Para Aratangy (2017), é de extrema importância que ao ter o primeiro contato com o indivíduo que pratica a automutilação, seja feita uma abordagem que o propicie uma reflexão a respeito de tal ato, com o objetivo de expor a gravidade do problema, alertando o paciente aos possíveis danos causados a si mesmo. Ainda segundo Aratangy (2017), o papel do profissional de saúde é mostrar ao paciente o que pode ser feito e o que não pode ser feito com relação a automutilação. Porém, diante disso, surge uma problemática importante: o Enfermeiro é capacitado para diagnosticar, acolher e orientar esses pacientes? Diante dos estudos, a maior parte, não. Por mais que a automutilação faça parte do Diagnóstico de Enfermagem, os profissionais tendem a fugir da objetividade e extrema sensibilidade que exige uma abordagem como esta. Isto porque, durante a formação acadêmica e, posteriormente, no mercado de trabalho, pouco se trata a respeito da automutilação, é um assunto desconhecido por muitos, o que causa grande aversão na maioria, dificultando a abordagem clínica e o tratamento. CONCLUSÃO: Com base na análise dos resultados e discussões, torna-se evidente que as comorbidades influenciam diretamente a automutilação, pois é a partir disso que se desencadeia os pensamentos e a prática automutilatória. $\mathrm{O}$ trabalho da enfermagem é imprescindível em todo o processo de diagnóstico, orientação e acompanhamento dos pacientes automutilatórios, tendo em vista que o Enfermeiro tem o contato inicial com essas pessoas e pode vir a desenvolver uma relação maior com os mesmos, com fins de oferecer métodos sucintos de tratamento e, posteriormente, o encaminhamento para um profissional de saúde mental. Todavia, para que isso ocorra, o Enfermeiro deve estar capacitado a lidar com estes pacientes de forma humana, empática e objetiva, sem pré-julgamentos e sem amenizar ou diminuir a situação. Um grande incentivo para que isso 


\section{ANAIS DA XVII SEMANA DE ENFERMAGEM DA UESPI}

ocorra é a recente aprovação da Lei $\mathrm{N}^{\mathrm{o}}$ 13.819, que determina a notificação compulsória, pelos estabelecimentos de saúde, aos casos de violência autoprovocada.

PALAVRAS-CHAVE: Automutilação, Perfil Epidemiológico, Diagnóstico de Enfermagem.

\section{REFERÊNCIAS}

ARATANGY, Eduardo Wagner. Como lidar com a automutilação: Guia prático para familiares, professores e jovens que lidam com o problema da automutilação. São Paulo: Hogrefe, 2017.

BRASIL. Lei No 13.819, de 26 de abril de 2019. Edição: 81 | Seção: 1 | Página: 1 Brasília-DF, 2019.

FREITAS, Elidiane Queiroz Merces. Automutilação na adolescência: prevenção e intervenção na psicologia escolar. Revista Ciência (In) Cena. On-line ISSN 2317-0816 Vol. 1 №. 5 Salvador. Bahia. 2017.

LOURENÇO, Vanessa Sofia Gonçalves. Para uma compreensão dos comportamentos de automutilação. Dissertação (Mestrado em Psicologia Aplicada) - Instituto Superior de Psicologia Aplicada. 2008. 72 p.

PEIXOTO, IC. Proposta de revisão do diagnóstico de enfermagem Automutilação da taxonomia NANDAI. TCC (Bacharelado em Enfermagem) - Departamento de enfermagem. Universidade de Brasília, Brasília, 2017; 29 p.

REIS, Maurício de Novais. Automutilação: o encontro entre o real do sofrimento e o sofrimento real. Revista Polêmica, v. 18, n. 1, p. 50-67, janeiro, fevereiro e março 2018. 


\section{ANAIS DA XVII SEMANA DE ENFERMAGEM DA UESPI}

\section{DO ESTRESSE OCUPACIONAL AO SURGIMENTO DA SÍNDROME DE BURNOUT EM PROFISSIONAIS DA ENFERMAGEM: UMA REVISÃO INTEGRATIVA}

Hernandes Flanklin Carvalho Oliveira $^{1}$, Magdiel da Costa Silva ${ }^{1}$, Suzana Honória de Sousa ${ }^{1}$, Raiane Araújo Brito ${ }^{1}$, Jhussara

Silva Alves ${ }^{1}$, Evelyne Ellene Alves de Carvalho ${ }^{1}$. E-mail: franklin.oliveira@yahoo.com

${ }^{1}$ Universidade Estadual do Piauí - UESPI, Floriano-PI, Brasil

Área temática: Temas Livre

INTRODUÇÃO: O ambiente de trabalho pode ser considerado um gerador de estresse, sendo o conjunto dessas desordens associadas a este ambiente, denominado de estresse ocupacional, aqui entendido como conflitos de ordem física e psicológica, capazes de afetar o indivíduo em seu contexto profissional, levandoo a um desequilíbrio gerador de respostas pouco adequadas. $\mathrm{O}$ estresse se interliga com a excessiva carga de trabalho e preocupações em virtude das exigências laborais. Não raros são os casos em que esse estresse ocupacional, ao não ser tratado, pode evoluir para o esgotamento físico e psicológico que caracterizam a Síndrome de Burnout, ligada ainda a falta de realização profissional e despersonalização. Nas duas últimas décadas, tem-se percebido um aumento gradativo de profissionais da enfermagem acometidos por altos níveis de estresse, sendo que geralmente são profissionais que se ocupam de uma quantidade expressiva de atividades na área da saúde, prestando cuidados aos clientes 24 horas do dia. OBJETIVO: Esta pesquisa tem como objetivo identificar como o estresse ocupacional pode desencadear a Síndrome de Burnout em profissionais da enfermagem. MÉTODOS: Trata-se de uma pesquisa descritiva, do tipo revisão de literatura, desenvolvida através de uma revisão integrativa, que de acordo com Mendes (2008) parte da análise de pesquisas relevantes, que poderão auxiliar a tomada de decisão e na melhoria da prática clínica, apontando possíveis soluções e abrindo a via do diálogo científico. Esta pesquisa foi realizada na Biblioteca Virtual em Saúde, no período de março a maio de 2019. Para a busca, utilizou-se os descritores: Estresse Ocupacional em Enfermeiros e Síndrome de Burnout em profissionais de Enfermagem, que direcionaram para 448 resultados. A partir disso, foram utilizados como critérios de inclusão: texto completo; publicados entre 2015 a 2019; tipo de documento artigo; foram encontrados 85 artigos. Logo após, foram excluídos os repetidos, não disponíveis gratuitos e que não contemplassem a temática, restando 9 artigos para análise de elaboração deste estudo, quais sejam, os que privilegiaram a temática de estudos amplos que abordam o estresse ocupacional e a Síndrome de Burnout associado ao trabalho da enfermagem, porém após a análise, alguns artigos não se enquadravam com o objetivo do trabalho, restando para a organização final, 5 artigos. RESULTADOS E DISCUSSÃO: Esse estudo baseou-se a partir de referências bibliográficas que embasaram o trabalho de Vidotti, et al. (2018) que realizou pesquisa com uma amostra de 502 profissionais da saúde, obtendo como resultado que os níveis da Síndrome de Burnout estão presentes em todos os turnos, porém, foram significativamente maiores entre os trabalhadores de enfermagem do turno diurno. Apontou ainda, que quem trabalha de dia, apresenta insatisfação com o sono, alta demanda e baixo controle sobre o trabalho, fatores que aumentaram significativamente as chances de alta exaustão emocional e a alta 


\section{ANAIS DA XVII SEMANA DE ENFERMAGEM DA UESPI}

despersonalização, que esteve associada aos enfermeiros sedentários e também indicou que, quanto maior a intensidade de exercícios físicos, menores os níveis de Burnout, ansiedade e depressão. Já na pesquisa de Mendeiros-Costa et al (2017) constou que muitas vezes, as pessoas que apresentam a Síndrome de Burnout, recebem diagnósticos de depressão ou outro transtorno mental, sem a devida ligação com o trabalho e quando existe interferência institucional ela é falha, apresentando apenas como foco capacitar os profissionais a enfrentar o estresse, e não para combatê-lo. Na literatura de Silva, et al. (2015) foi realizada uma pesquisa com 163 profissionais de enfermagem onde afirmou-se que a despersonalização dos profissionais foi destaque como a dimensão mais afetada do Burnout, que são atitudes de frieza, dureza, insatisfação com o trabalho, distanciamento para com os pacientes e companheiros de trabalho. Scholze, et al. (2017) ressaltam em seus achados que as mulheres têm mais suscetibilidade ao estresse, devido estarem expostas à dupla jornada de trabalho, levando em consideração a realização das atividades associadas ao trabalho e também pelas atribuições do lar. Além disso, o trabalho com alta demanda tem vários fatores associados que acarretam significativamente as chances dos enfermeiros perceberem seus trabalhos como estressantes, bem como a percepção negativa dos serviços de apoio à assistência prestada ao paciente, eficácia dos programas de educação continuada, tempo e oportunidades para debater com outros colegas de trabalho os problemas provenientes dos cuidados prestados ao cliente. Rodrigues, Santos e Sousa (2017) afirmam que o estresse ocupacional e a Síndrome de Burnout vivenciadas por profissionais de enfermagem provocam maior vulnerabilidade no desenvolvimento de assistência insegura e que a falta de assentimento institucional coopera para um ambiente de trabalho estressante, bem como a carga de trabalho excessiva enquanto causadora de falhas. CONCLUSÃO: Diante do exposto, evidencia-se a necessidade de as instituições de saúde desenvolverem ações concretas que visem à prevalência sadia da saúde do profissional de enfermagem em toda esfera social, principalmente no seu ambiente laboral. Outrossim, no desenvolver de atividades educacionais amplas, como continuadas e permanentes, e, principalmente discussões com esses profissionais que estão expostos diretamente com os problemas, abordando os efeitos na sua saúde que apresenta uma peculiaridade de vida saudável, para que assim, os profissionais venham a desenvolver suas atividades e cooperar onde for necessário. Portanto, o enfermeiro (a), deve primeiramente ter sua saúde em perfeito estado e saber reconhecer e tratar quando a mesma é falha, para poder assim, desenvolver sua importante função.

PALAVRAS-CHAVE: Estresse Ocupacional, Profissionais de Enfermagem, Burnout.

\section{REFERÊNCIAS:}

MEDEIROS-COSTA, Mateus Estevam; MACIEL, Regina Heloísa Maciel; RÊGO, Denise Pereira do; LIMA, Lucimar Lucas de; SILVA, Maria Eliziane Pinto da; FREITAS, Julyana Gomes. A síndrome do esgotamento profissional no contexto da enfermagem: uma revisão integrativa da literatura. Revista da Escola de Enfermagem da USP, 2017;51:e03235. Disponível em: 〈www.ee.usp.br/reeusp>. Acesso em 28 de abril de 2019. 


\section{ANAIS DA XVII SEMANA DE ENFERMAGEM DA UESPI}

MENDES, Karina Dal Sasso; SILVEIRA, Renata Cristina de Campos Pereira; GALVÃO, Cristina Maria. Revisão integrativa: método de pesquisa para a incorporação de evidências na saúde e na enfermagem. Texto contexto - enfermagem. Florianópolis, v. 17, n. 4, Dec. 2008. Disponível em <http://dx.doi.org/10.1590/S0104-07072008000400018>. Acesso em 08 de maio de 2019.

RODRIGUES, Cláudia Cristiane Filgueira Martins; SANTOS, Viviane Euzébia Pereira; SOUSA, Paulo. Segurança do paciente e enfermagem: Interface com estresse e Síndrome de Burnout. Revista Brasileira de Enfermagem-REBEn, 2017;70(5):1083-8. Disponível em: < http://dx.doi.org/10.1590/0034-71672016-0194>. Acesso em 28 de abril de 2019.

SCHOLZE, Alessandro Rolim; MARTINS, Julia Trevisan; ROBAZZI, Maria Lucia do Carmo Cruz; HADDAD, Maria do Carmo Fernandez Lourenço; GALDINO Maria José Quina; RIBEIRO Renata Perfeito. Estresse ocupacional e fatores associados entre enfermeiros de hospitais públicos. Cogitare Enfermagem. (22)3: e50238, 2017. Disponível em: < http://dx.doi.org/10.5380/ce.v22i3.50238>. Acesso em 28 de abril de 2019.

SILVA, Renata Pimentel da; BARBOSA, Silvânia da Cruz; SILVA, Sandra Souza da; PATRÍCIO, Danielle Figueiredo. Burnout e estratégias de enfrentamento em profissionais de enfermagem. Arquivos Brasileiros de Psicologia; Rio de Janeiro, 67 (1): 130-145, 2015. Disponível em: <http://pepsic.bvsalud.org/scielo.php?script=sci_arttext\&pid=S1809-52672015000100010 >. Acesso em 28 de Abril de 2019.

VIDOTTI, Viviane; RIBEIRO, Renata Perfeito; GALDINO, Maria José Quina; MARTINS, Julia Trevisan. Síndrome de Burnout e o trabalho em turnos na equipe de enfermagem. Revista LatinoAmericano de Enfermagem, 2018;26:e3022. Disponível em: < www.eerp.usp.br/rlae>. Acesso em 28 de abril de 2019. 


\section{ANAIS DA XVII SEMANA DE ENFERMAGEM DA UESPI}

\section{A DEPRESSÃO PÓS-PARTO E OS PRINCIPAIS FATORES ASSOCIADOS AO SEU DESENVOLVIMENTO}

Ana Maria da Costa Oliveira ${ }^{1}$, Alessandra Beltrami Oliveira ${ }^{1}$, Laís Alves de Sousa ${ }^{1}$, João Victor de Sousa Lima ${ }^{1}$, Suzana Honória de Sousa ${ }^{1}$, Evelyne Ellene Alves de Carvalho'. E-mail: anamaria_o@outlook.com

${ }^{1}$ Universidade Estadual do Piauí - UESPI, Floriano-PI, Brasil

Área temática: Temas Livre

INTRODUÇÃO: O puerpério é um período que ocorre após o parto e pode durar em média 45 dias, dependendo da mulher. Esta variabilidade está relacionada pelas díspares alterações físiológicas, anatômicas, hormonais e psicológicas que ocorrem nas mulheres nesse período (BRASIL, 2016). Estas modificações, além da experiencia nova com a maternidade e a ansiedade que foi despertada com a chegada do bebê, podem atingir a saúde mental das puérperas e o seu bem-estar psicológico, tornandoas mais sucessíveis a desenvolver transtornos psiquiátricos. A Depressão Pós-Parto (DDP) é considerada o principal transtorno psiquiátrico que acomete as mulheres no período gravídico-puerperal (ABUCHAIM, et al. 2016). OBJETIVO: Analisar a depressão pós-parto e os principais fatores associados ao seu desenvolvimento. MÉTODOS: Trata-se de uma revisão bibliográfica, de caráter descritivo, a respeito dos fatores associados a prevalência da depressão puerperal nas mulheres, cujo método de levantamento bibliográfico baseou-se em artigos científicos disponíveis na plataforma virtual Scielo (Scientific Electronic Library Online). Ademais, foi utilizado a literatura Protocolos de Atenção Básica a Saúde das Mulheres (2016). Foram utilizados os seguintes descritores: Puerpério, Depressão Pós-parto, Fatores associados a DPP. Os dados foram coletados no período de abril e maio de 2019. Os critérios para seleção dos trabalhos foram: artigos com base de dados nacionais, entre os anos de $2014 \mathrm{e}$ 2019 e que se relacionavam com a proposta do estudo. Para a construção do estudo foram selecionados inicialmente 18 artigos, no entanto, apenas 5 destes foram utilizados, pois se relacionavam melhor com o tema. A cronologia para o presente artigo foi: delimitação do tema, pesquisa dos artigos, leitura criteriosa dos trabalhos, seleção e resumos. RESULTADOS E DISCUSSÃO: Essa pesquisa baseou-se a partir de literaturas que embasaram o trabalho de Hartmann, Mendoza-Sassi e Cesar (2017) que relatam em seus resultados que uma em cada sete gestantes foram afetadas por depressão. Os fatores desencadeadores apontados foram gravidez na adolescência, multiparidade, histórico de depressão na gestação ou presente na família, falta de suporte familiar e social, intensa ansiedade, perdas gestacionais anteriores e sentimentos negativos quanto à gestação ou em relação ao bebê. Todavia, a maior idade, a assistência profissional anterior ao parto e o suporte da equipe de saúde durante o parto serviram como fatores de proteção. Foram apontados, ainda, outros fatores de risco que estão relacionados a Depressão Pós-Parto, sendo eles o acontecimento da gravidez não planejada, alto nível de estresse, histórico de abuso ou violência doméstica e perda fetal. Ademais, dificuldade financeira pode também ter relação no 


\section{ANAIS DA XVII SEMANA DE ENFERMAGEM DA UESPI}

desenvolvimento da DPP, assim como baixa escolaridade e estado de desemprego (LIMA, et al., 2017). Segundo Abuchaim (2016), em uma busca por identificar sintomatologia a depressão pós-parto na população a qual foi estudada, percebeu-se uma maior prevalência dos sintomas de culpa, ansiedade e angústia. As evidências indicam um impacto que a depressão tem na vida das mulheres para curto e a longo período, principalmente na saúde mental e para consequências negativas que podem ser acarretados. Nesse aspecto, a relação com o bebê pode ser comprometida negativamente, podendo interferir no desempenho do aleitamento, prática fundamental na saúde da criança. Os resultados apresentados por Lima (2017), mostram a necessidade de atenção direcionada para a saúde mental, desde o princípio da gestação durante a assistência pré-natal, propondo estratégias de atendimento à mulher de maneira especializada, utilizando como instrumento de identificação dos sintomas depressivos a Escala de Depressão Pós-parto de Edimburgo. De acordo com estudos de Meira (2015), as profissionais que fazem parte da Estratégia Saúde da Família vivenciam situações durante a assistência nas quais mulheres estão possivelmente com DPP. Todavia, apresentaram dificuldade para identificar a DPP, de forma que seja possível prevenir ou tratar precocemente, pois não conhecem os métodos de identificação e têm formas de intervir limitadas, por não terem a constatação da doença. Os estudos demonstram que a DPP é um problema que não se manifesta de forma tão aparente, portanto é um campo aberto e amplo a ser pesquisado, sendo uma realidade cada vez mais corriqueira no ambiente de trabalho dos profissionais de saúde da Atenção Básica, e estão situados em uma posição propícia a detectar precocemente e intervir, de forma a evitar o agravamento da DPP (ARRAIS e ARAÚJO, 2017). CONCLUSÃO: De acordo com o exposto, conclui-se que os principais fatores associados são: presença de depressão no período gestacional ou no histórico familiar, ausência de suporte durante o período gravídico por parte social ou do parceiro, baixa renda socioeconômica e complicações gestacionais. Nota-se que é preciso haver um maior suporte durante o período gravídico, por meio de estratégias de atendimento à mulher de forma especializada no âmbito da saúde e social. A alta dominância de DPP encontrada reforça a importância de tratar como problema de saúde pública, requerendo métodos para prevenir e tratar o problema. O acompanhamento atencioso às mães, especialmente as de baixa renda, através de ação incorporada que leve em conta os fatores associados à depressão, pode precaver graves problemas que sucedem da DPP.

PALAVRAS-CHAVE: Gestação, Puerpério, Depressão Pós-parto.

\section{REFERÊECIAS:}

ABUCHAIM, Erika de Sá Vieira; CALDEIRA, Nathalia Torquato; DI LUCCA, Marina Moraes; VARELA, Maite; SILVA, Isília Aparecida. Depressão pós-parto e autoeficácia materna para amamentar: prevalência e associação. Acta Paulista de Enfermagem São Paulo, 2016. 


\section{ANAIS DA XVII SEMANA DE ENFERMAGEM DA UESPI}

ARRAIS, Alessandra da Rocha; ARAUJO, Tereza Cristina Cavalcanti Ferreira. Depressão pós-parto: uma revisão sobre fatores de risco e de proteção. PSICOLOGIA, SAÚDE \& DOENÇAS, Sociedade Portuguesa de Psicologia da Saúde - SPPS, 2017.

BRASIL, Ministério da Saúde. Protocolos da Atenção Básica: Saúde das Mulheres / Ministério da Saúde, Instituto Sírio-Libanês de Ensino e Pesquisa - Brasília: Ministério da Saúde, 2016.

HARTMANN, Juliana Mano; MENDONZA-SASSI, Raul Andrés; CEZAR, Juraci Almeida. Depressão entre puérperas: prevalência e fatores associados. Cadernos de Saúde Pública 2017.

LIMA, Marlise de Oliveira Pimentel; TSUNECHIRO, Maria Alice; BONADIO, Isabel Cristina; MURATA, Marcella. Sintomas depressivos na gestação e fatores associados: estudo longitudinal. Acta Paulista de Enfermagem, São Paulo, 2017.

MEIRA, Bianca de Macêdo; PEREIRA, Pauliany Alencar de Souza; SILVEIRA, Maria de Fátima Araújo; GUALDA, Dulce Maria Rosa; JÚNIOR, Hudson Pires Oliveira Santos. Desafios para profissionais da atenção primária no cuidado à mulher com depressão pós-parto. Texto Contexto Enfermagem, Florianópolis, 2015 Jul-Set; 24(3): 706-12. 


\section{ANAIS DA XVII SEMANA DE ENFERMAGEM DA UESPI}

\section{ANALISE MICROBIANA DOS ALIMENTOS OFERECIDOS EM ESCOLAS PÚBLICAS DA CIDADE DE FLORIANO - PI}

Autores: Matheus Lima dos Reis Sousa ${ }^{1}$, Bianca Leite Carnib de Sousa ${ }^{1}$, Pedro Samuel Rodrigues Rego ${ }^{2}$, Yanez André Gomes Santana ${ }^{1}$. E-mail: matheus_lima02@ hotmail.com

Instituição: Universidade Federal do Piauí-UFPI, Floriano-Piauí, Brasil ${ }^{1}$, Faculdade de Floriano-FAESF, Floriano-Piauí, Brasil $^{2}$

Eixo temático: Temas livres

INTRODUÇÃO: As doenças transmitidas por alimentos ocorrem pela ingestão de água ou alimentos contaminados com agentes químicos ou biológicos (AMSON et al., 2006; SANTOS et al., 2015). A contaminação de alimentos com águas também deve ser considerada, pois, se nestas estiverem presentes microrganismos patogênicos, poderão causar doenças, comprometendo a saúde dos consumidores (JERBA \& PILEGGI, 2000).Vários métodos podem ser utilizados para detectar microrganismos em alimentos, A técnica do Número Mais Provável (NMP) é uma maneira muito utilizada pelos laboratórios de análises de alimentos. Esse método serve para a contagem de microrganismos, obtendo informações sobre a população presuntiva de coliformes (teste presuntivo), a respeito do número real da população (teste confirmativo) de coliformes totais e de coliformes fecais (FRANCO \& LANDGRAF, 2005; SIQUEIRA, 1995). O Programa Nacional de Alimentação Escolar (PNAE) foi criado com o intuito de participação popular no conjunto das ações de gestão, a distribuição e fornecimento de merenda escolar, segurança alimentar, garantindo alimentos sem agentes contaminantes (CONSEA,2007) (BRASIL,2009). Em Floriano, o PNAE atende cerca de 13.500 alunos, distribuído em 68 escolas estaduais e municipais, de acordo com o censo escolar de 2018. Deste modo, é de suma importância saber como os alimentos são armazenados, manejados, conservados, higienizados e preparados, por parte das escolas, com o intuito de garantir a qualidade sanitária da alimentação dos alunos. A alimentação de qualidade, tendo por vista o direito insubstituível previsto na Constituição Federal, por meio do PNAE, garantindo assim uma refeição livre de agentes contaminantes e também uma alimentação bem nutritiva. OBJETIVO: O presente trabalho teve o propósito de avaliar a qualidade microbiológica dos alimentos ofertados nas escolas da cidade de Floriano-PI com base na Resolução-RDC nº 12/2001 do Ministério da Saúde que se refere aos padrões microbiológicos para alimentos, utilizando o método do Número Mais Provável (MNP) para coliformes fecais e termotolerantes. MÉTODO: A coleta do material foi realizada em duas escolas públicas estaduais da cidade de Floriano-Piauí, a Unidade Escolar Bucar Neto e na Unidade Escolar Osvaldo da Costa e Silva. Foram coletadas sete amostras de alimentos ofertados no dia em cada escola no período de 180 dias. As amostras foram coletadas em frascos de vidro estéreis, os mesmos foram lavados, secos e embalados em papel grau cirúrgico e esterilizados em autoclave a $120^{\circ} \mathrm{c}$ durante 15'. Inicialmente realizou-se a antissepsia das mãos, em seguida o frasco era aberto próximo ao local de coleta do alimento, onde era colhido cerca de $150 \mathrm{~g}$ da amostra. Logo após o recipiente era 


\section{ANAIS DA XVII SEMANA DE ENFERMAGEM DA UESPI}

fechado e encaminhado ao Laboratório de Microbiologia da Universidade Federal do Piauí - Campus Amílcar Ferreira Sobral, onde foram analisadas. Foram realizadas as análises Número Mais Provável $(\mathrm{NMP} / \mathrm{g})$ de coliformes totais $\left(37^{\circ} \mathrm{C}\right)$ e termotolerantes/fecais $\left(44^{\circ} \mathrm{C}\right)$, trata-se de um teste qualitativo de tubos múltiplos que se baseia na capacidade das bactérias do grupo coliforme em fermentar a lactose, produzindo gases que são evidenciados ao fim do processo. A primeira fase da análise foi a realização teste para coliformes totais, para tal $25 \mathrm{~g}$ da amostra foi transferido assepticamente com auxílio de pipeta graduada previamente esterilizada para um Becker também previamente esterilizado contendo $225 \mathrm{ml}$ de solução salina peptonada $0,1 \%$, em seguida $1 \mathrm{ml}$ desta solução foi inoculado em cada um dos três tubos de ensaio com tubo de Durah invertido contendo $7 \mathrm{ml}$ de caldo Lauril Sulfato Triptose (LST), e um tubo contendo $7 \mathrm{ml}$ de solução salina peptonada $0,1 \%$, homogeneizados em vortex durante 30 segundos formando a diluição $10^{-1}$, repetindo o processo até a obtenção da diluição $10^{-3}$. As amostras foram incubadas em estufa bacteriológica a $37^{\circ} \mathrm{C}$ por 24 a $48 \mathrm{~h}$. Na fase seguinte ocorreu a efetuação dos testes confirmativos utilizando-se os meios de cultura caldo Verde Brilhante Bile Lactosado (VBBL) para determinação de coliformes termotolerantes, e caldo EC para Escherichia coli. Com auxílio da alça de platina transferiu-se material das amostras com resultado positivo no caldo LST para tubos contendo caldo VBBL e incubados em estufa bacteriológica a $37^{\circ} \mathrm{C}$ por 24 a $48 \mathrm{~h}$, e para caldo EC e incubados em banho Maria a $44^{\circ} \mathrm{C}$ por 24 a $48 \mathrm{~h}$. Os procedimentos de inoculação das amostras eram realizados em capela de fluxo laminar para evitar possíveis contaminações do meio, após o período de incubação procedia-se a anotação dos dados obtidos foram consideradas positivos os quais a presença de gás e turvação após esse período confirmou a presença de coliformes. RESULTADO e DISCUSSÃO: Observamos que nas amostras da Unidade Escolar Osvaldo da Costa e Silva existe uma diferença significativa na presença de Escherichia coli e coliformes termotolerantes em alguns alimentos apresentaram valor maior que 1100 $\mathrm{NMP} / \mathrm{g}$, manifestando uma alta taxa de contaminação, certamente devido ao modo de preparo, como o cozimento e o manejo. Nos resultados obtidos na Unidade Escolar Bucar Neto, apenas duas amostras estavam contaminadas com E. coli e uma com coliformes totais, mostrando que os alimentos que tem um cozimento adequado e um manejo correto. Já na Unidade Escolar Osvaldo da Costa e Silva, quatro amostras estavam contaminadas com E. coli e quatro com coliformes totais. É possível observar que os requisitos higiênicos sanitárias não estão em um nível satisfatório. Deschamps et al. (2003) ressaltam a importância do controle entre temperatura/tempo, pois é essencial para um melhor monitoramento sanitário durante o processo de produção, podendo evitar o aumento exponencial de microrganismos patogênicos. A temperatura é um dos principais fatores que afetam a qualidade e a multiplicação microbiana, o aquecimento torna-se uma linha de defesa indispensável na prevenção de DTAs (DEUS et al. 2005). CONCLUSÃO: Destacamos que estudos como esse são de relevante importância, pois se podem avaliar as condições de higienização, buscando minimizar os ricos de contaminação ligados a ao consumo de alimentos oferecidos na merenda escolar. 


\section{ANAIS DA XVII SEMANA DE ENFERMAGEM DA UESPI}

PALAVRAS-CHAVE: Alimentação Escolar, Coliformes, Ingestão de Alimentos.

\section{REFERENCIAS:}

BRASIL. Resolução CD/FNDE n⿳38, de 23 de agosto de 2009. Dispõe sobre o atendimento da alimentação escolar aos alunos da educação básica no Programa Nacional de Alimentação Escolar - PNAE. Brasília-DF: Ministério da educação.

CONSELHO NACIONAL DE SEGURANÇA ALIMENTAR E NUTRICIONAL (CONSEA). III Conferência Nacional de Segurança Alimentar e Nutricional. CONSEA: Brasília, 2007, p.44.

DEUS M.B., HOLLAND N. , MORAES C.M.M., STAMFORD T.L.M. Microrganismos patogênicos e temperaturas de exposição de carne bovina servida em restaurantes self-service da cidade de Natal-RN. 1(4):237-45. Brasil. Revisa. 2005;

FRANCO, B.D.G.M., LANDGRAF, M. Microbiologia dos alimentos. São Paulo: Atheneu, 2005. JERBA, V. F.; PILEGGI, M. ÁGUA: TRANSPORTE PASSIVO DE MICRORGANISMO?. V.1, n.6, p. 21-27. . Ponta Grossa - PR: Biological and Health Sciences, 2000.

SIQUEIRA, R.S. Manual de microbiologia de alimentos. Brasília: EMBRAPA, SPI; Rio de Janeiro: EMBRAPA, CTAA, 1995. 159p. 


\section{ANAIS DA XVII SEMANA DE ENFERMAGEM DA UESPI}

\section{ASSISTÊNCIA DE ENFERMAGEM AO PACIENTE COM DERRAME PLEURAL: RELATO DE EXPERIÊNCIA}

Autores: Kellícia Rocha Arrais ${ }^{1}$, Julyanne dos Santos Nolêto $^{2}$. E-mail: kelliciaarrais@ gmail.com

Instituição: ${ }^{1}$ Universidade Estadual do Piauí (UESPI), Floriano - PI, Brasil. ${ }^{2}$ Universidade Federal do Piauí (UFPI), Teresina - PI, Brasil.

Eixo temático: Boas Práticas de Enfermagem na assistência, ensino, pesquisa e gestão.

INTRODUÇÃO: O derrame pleural consiste em uma coleção de líquido no espaço pleural. Raramente constitui um processo patológico primário, é habitualmente secundário a outras doenças, são elas: insuficiência cardíaca, tuberculose, pneumonia, infecções pulmonares (principalmente as infecções virais), síndrome nefrótica, doença do tecido conjuntivo, embolia pulmonar e tumores neoplásicos. Em geral, as manifestações clínicas são causadas pela doença subjacente. A pneumonia provoca febre, calafrios e dor torácica, enquanto o derrame maligno pode resultar em dispneia, dificuldade em deitar na posição horizontal e tossir. A gravidade dos sintomas é determinada pelo tamanho do derrame, pela velocidade de sua formação e pela doença pulmonar subjacente. A presença de líquido no espaço pleural é confirmada pela radiografia e ultrassonografia torácica e a toracocentese. $\mathrm{O}$ tratamento é direcionado para a causa subjacente, além da drenagem torácica para evacuar o espaço pleural e expandir o pulmão (BRUNNER e SUDDARTH, 2015). OBJETIVO: Relatar a experiência no cuidado ao paciente com derrame pleural. MÉTODO: Trata-se de um estudo descritivo, com abordagem qualitativa, tipo relato de experiência da vivência de uma acadêmica de enfermagem da Universidade Estadual do Piauí, no Estágio da disciplina Trabalho em Campo "Saúde do Adulto e do Idoso II", no turno da manhã, em novembro de 2017. Utilizou-se a entrevista, os métodos propedêuticos, além do prontuário do paciente. O cenário foi um Hospital Público de referência em urgência e emergência, Floriano-PI. A experiência envolveu a implementação do Processo de Enfermagem utilizando-se os diagnósticos de Enfermagem da Associação Norte Americana de Diagnósticos de Enfermagem (NANDA) a um paciente com derrame pleural. Para respaldar o Processo de Enfermagem foi adotada a Teoria das Necessidades Humanas Básicas. RESULTADOS E DISCUSSÃO: No primeiro momento realizou-se a entrevista e em seguida o exame físico. Verificou-se como problemas de enfermagem: presença de líquido no espaço pleural, murmúrios vesiculares diminuídos, alimentação por sonda, vias invasivas de dreno de tórax e acesso venoso central, imobilidade física e lesão por pressão. Com base nos Diagnósticos de Enfermagem da NANDA, obtiveram-se os seguintes diagnósticos prioritários: Desobstrução ineficaz das vias aéreas relacionado a secreções retidas caracterizado por sons respiratórios diminuídos. Risco de aspiração relacionado à alimentação enteral. Risco de infecção relacionado à procedimento invasivo. Integridade da pele prejudicada relacionada à pressão sobre saliência óssea caracterizada por alteração na integridade da pele. início da alimentação/realizar a dieta ente trinta minutos a uma hora antes do banho do leito e 


\section{ANAIS DA XVII SEMANA DE ENFERMAGEM DA UESPI}

exames/ monitorar a função gastrointestinal/ avaliar o posicionamento da sonda), minimizar exposição a agentes patogênico (manter as técnicas assépticas, verificar sinais vitais de 6/6h), apresentar integridade da pele melhorada (realizar e anotar curativo da lesão por pressão, mudança de decúbito de duas em duas horas, proteger proeminências ósseas, avaliar diariamente a pele e orientar a troca de fraldas). $\mathrm{Na}$ taxonomia da NANDA-I (2018) o diagnóstico de enfermagem Desobstrução ineficaz das vias aéreas é definido como a "incapacidade de eliminar secreções ou obstruções do trato respiratório para manter a via aérea desobstruída". Segundo Andrade et al. (2014), em geral, a identificação desse e outros diagnósticos respiratórios são prioritários, por atingir diretamente a oxigenação tissular, o que demanda intervenções rápidas e resolutivas. Sobre o Risco de aspiração tido como a "suscetibilidade à entrada de secreções gastrintestinais, secreções orofaríngeas, sólidos ou líquidos nas vias traqueobrônquicas que possa comprometer a saúde" (NANDA, 2018), uma pesquisa trouxe a associação desse diagnóstico de enfermagem e seus fatores de risco em pacientes internados em unidade de terapia intensiva. Na qual elencou-se como fatores de risco: deglutição prejudicada, sonda gastrintestinal, alimentação por sonda, nível de consciência reduzido, presença do tubo intratraqueal, eventos secundários relacionados ao tratamento, esvaziamento gástrico retardado e resíduo gástrico aumentado (BISPO, 2016). Desse modo, salienta-se que o estudo e a implementação dos diagnósticos de enfermagem possibilita ao enfermeiro identificar os fatores de risco e sistematizar a assistência, e por conseguinte proporcionar a qualidade na prestação dos cuidados. O diagnóstico de enfermagem Risco de infecção é descrito como a "suscetibilidade a invasão e multiplicação de organismos patogênicos que pode comprometer a saúde" (NANDA, 2018), de acordo com Pena e Melleiro (2017) evidencia-se na sua pesquisa a prevalência de flebites, tendo como causa principal o déficit no processo de comunicação entre as equipes. Logo, faz-se necessário instituir o aperfeiçoamento da cultura de segurança do paciente. Sobre o diagnóstico Integridade da pele prejudicada definida como "Epiderme e/ou derme alterada" (NANDA, 2018), Serpa, Santos e Paranhos (2014) relatam que as consequências advindas das lesões por pressão, representam aumento de morbidade e mortalidade, o que desperta para relevância da prevenção, por meio de estratégias que visem à redução da exposição aos fatores de risco e aumento da proteção do indivíduo. Ao se utilizar a Teoria das Necessidades Humanas Básicas, observou-se que o processo de enfermagem alcança os objetivos propostos, uma vez que, os diagnósticos de enfermagem elencados pertencem ao domínio segurança/proteção, na qual infere-se na dimensão psicobiológica. CONCLUSÃO: A identificação dos diagnósticos de enfermagem permitiu o conhecimento das necessidades de cuidados de enfermagem e o direcionamento da assistência, possibilitando o estabelecimento do plano de cuidados individual e holístico. Percebe-se que a assistência de enfermagem para ser efetiva deve ser sistemática e inter-relacionada com o Processo de Enfermagem, buscando avaliar os achados clínicos e através dos mesmos implementar os cuidados de enfermagem. Ademais, este estudo possibilitou uma aproximação com o campo prático e o desenvolvimento de uma assistência humanizada. 


\section{ANAIS DA XVII SEMANA DE ENFERMAGEM DA UESPI}

PALAVRAS-CHAVE: Derrame Pleural, Processo de Enfermagem, Cuidados de Enfermagem.

\section{REFERENCIAS}

ANDRADE, L.Z.C. et al. Desobstrução ineficaz de vias aéreas: prevalência e espectro de seus indicadores clínicos. Acta Paulista Enfermagem, v.27, n.4, p.319-325, 2014. Disponível em: DOI: http://dx.doi.org/10.1590/19820194201400054. Acesso em: 25 Abril 2019.

BISPO, M.M. et al. Diagnóstico de enfermagem risco de aspiração em pacientes críticos. Escola Anna Nery, v.20, n.2, p.357-362, 2016. Disponível em: DOI: 10.5935/1414-8145.20160049. Acesso em: 25 Abril 2019.

BRUNNER, L. S.; SUDARTH, D. S. Tratado de Enfermagem Médico - Cirúrgico. $13^{\text {a }}$ ed. Rio de Janeiro: Guanabara Koogan, 2015.

NANDA. Diagnósticos de enfermagem da NANDA-I: definições e classificação 2018-2020. $11^{\text {a }}$ ed. Porto Alegre: Artmed, 2018.

PENA, M. M.; MELLEIRO, M. M. O método de análise de causa raiz para a investigação de eventos adversos. Revista Enfermagem UFPE, v. 11, n.12, p.5297-5304, 2017. Disponível em: DOI: 10.5205/1981-8963-v11i12a25092p5297-5304-2017. Acesso em: 25 Abril 2019.

SERPA, L.F.; SANTOS, V.L.C.G.; PARANHOS, W.Y. Escalas de avaliação de risco para o desenvolvimento de úlcera por pressão. In: BLANES, L.; FERREIRA, L.M. Prevenção e tratamento de úlcera por pressão. São Paulo: Editora Atheneu, 2014. 


\section{ANAIS DA XVII SEMANA DE ENFERMAGEM DA UESPI}

\section{DESENVOLVIMENTO E ANÁLISE FÍSICO - QUÍMICO DA PLANTA CITRONELA COMO REPELENTE VEICULADO EM GEL CREME}

Autores: Aludy Karina de Carvalho Costa. E-mail: aludy12@ hotmail.com.

Instituição: Faculdade de Ensino Superior de Floriano-FAESF, Oeiras-PI, Brasil.

Eixo temático: temas livres.

INTRODUÇÃO: Mais de 700 milhões de pessoas a cada ano são afetadas por mosquitos que transmitem doenças ${ }^{1}$. De acordo com a OMS, dois quintos da população estão sob risco de serem infectados pelo vírus da dengue, sendo que mais de 100 países têm sido atingidos por epidemias de dengue e dengue hemorrágica ${ }^{2}$. O uso de repelentes contra picada de insetos é um dos métodos utilizados na prevenção e minimização da incidência de doenças transmitidas por artrópodes ${ }^{3}$, como é o caso da dengue, cujo agente transmissor do vírus é o mosquito Aedes aegypti. Em muitas situações, o uso de repelentes representa o único artifício capaz de impedir a transmissão da doença, sabendo que uma única picada por mosquito infectado é capaz de contaminar o indivíduo (TUETUM et al. 2005; FRADIN, 2002). A citronela é vista como um repelente natural e ecológico, devido espantar os insetos sem matá-los. Sendo assim, se torna uma maneira de afastar a doença sem prejudicar a natureza, uma vez que o Aedes aegypti faz parte do ecossistema e não pode ser extinto sob a pena de causar um desequilíbrio ambiental (GIOPPO; SILVA; BARRA, 2006). Segundo Ponzio (2001), a forma farmacêutica gel-creme é de fácil aplicação e espalhabilidade, além de causar na pele uma sensação boa e a necessidade de reaplicações são menores. OBJETIVOS: geral: preparar formulação de um repelente em gel creme à base da planta citronela e analisar os seus aspectos físico-químico. Específico: caracterizar os constituintes da formulação e interpretar os resultados obtidos para concluir se a formulação está de acordo com o esperado. MÉTODO: O tipo de abordagem metodológica é descritiva, quali-quantitativa e de forma experimental, onde se reproduziu em laboratório uma formulação de gel-creme repelente a base de Citronela, utilizando matérias-primas onde se aplicaram métodos analíticos físico-químico, obtendo assim as características que este tipo de produto apresenta. O preparo da formulação e avaliação físico-químico constituída pelo princípio ativo Citronela (Cymbopogon winterianus) na forma farmacêutica gel-creme, foram realizadas no Laboratório de Controle de Qualidade do Laboratório Farmacêutico Sobral, que fica localizado no município de Floriano-PI. Os excipientes utilizados no preparo do creme, foram cedidos pelo Laboratório Sobral, tendo todos eles sido analisados e aprovados pelo Controle de Qualidade do Laboratório. Manipulação e processo: fase 1: foi diluído o Polawax com q.s.p. 100\% de água sob leve aquecimento $\left(25^{\circ} \mathrm{C}\right)$ até a formação do gel. Subsequente foi adicionado o EDTA previamente diluído, homogeneizado constantemente e aquecido até $\left(45^{\circ} \mathrm{C}\right)$. Fase 2 : O propilenoglicol e o metilparabeno fundido e adicionado na fase 1. Fase 3: Depois de fundido em banho-maria a temperatura de $80^{\circ} \mathrm{C}$ foi adicionado o monoestearato de glicerila e o álcool cetoestearílico que pertencem a parte oleosa. Adicionado nas fases 


\section{ANAIS DA XVII SEMANA DE ENFERMAGEM DA UESPI}

1 e 2 e homogeneizado por 8-10 minutos para o choque e a formação do creme. Foi submetido a alta rotação por 10 segundos. Fase 4: Resfriamento por 20 minutos ou até atingir $45^{\circ} \mathrm{C}$. Fase 5: Foi misturado o Cetiol V e metabissulfito de sódio e adicionado nas fases anteriores e homogeneizado por 10 minutos. Fase 6: Deixou-se o gel-creme a temperatura de $35^{\circ} \mathrm{C}$ para posteriormente adicionar o Óleo de Citronela. Fase 7: Deixou estabilizar. Fase 8: Controle de qualidade (pH, viscosidade, centrifugação, avaliação macroscópica). Fase 9: Envasado. Análise físico-químico: As análises foram realizadas no Controle de Qualidade do Laboratório Industrial Farmacêutico Sobral. As análises realizadas são de grande importância, pois, são através delas que o produto terá a garantia de qualidade e segurança que necessita. Foram realizadas as seguintes análises para o controle de qualidade. Sendo a primeira análise, o $\mathrm{pH}$. Posteriormente a viscosidade, em viscosímetro de Brookfield, e o teste de centrifugação do gel-creme.

RESULTADOS E DISCUSSÃO: Este trabalho buscou avaliar as características do gel-creme como repelente a base de Citronela, através de análises de $\mathrm{pH}$, viscosidade, teste de centrifugação e características organolépticas. Dados analíticos: aspecto: gel-creme; homogêneo. Cor: branco; Odor: característico de Citronela; pH: 5,0 - 6,0; Viscosidade: conforme padrão (alta viscosidade). Resultado das análises: aspecto: de acordo, ou seja, gel-creme; homogêneo. Cor: branco. Odor: característico de Citronela. pH: 5,41. Viscosidade: alta viscosidade. Teste de centrifugação: estável e homogêneo. Teste de centrifugação: Este gel-creme foi submetido a uma rotação de 3000 rpm por 30 minutos no teste de centrifugação, permanecendo estável e homogêneo, não necessitando assim, de reformulação. A pele não possui $\mathrm{pH}$ neutro, e dependendo da região do corpo ou da idade, o pH varia, mas, no geral, o chamado pH fisiológico da pele é entre (4,5 - 6,0), onde contribui para que ocorra proteção bactericida e fungicida em sua superfície. $\mathrm{O} \mathrm{pH}$ do gel-creme repelente, apresentou-se dentro do escopo estipulado para o produto que fica entre $(5,0-6,0)$. Além disso, este $\mathrm{pH}$ fica dentro do $\mathrm{pH}$ fisiológico da pele que é de $(4,5$ - 6,0), tornando assim um produto seguro para o uso. CONCLUSÃO: O resultado da formulação do gel-creme à base de Citronela como repelente, ficou dentro das expectativas iniciais para o produto em questão sendo uma opção viável. A Citronela é um repelente seguro e bastante utilizado, por ser de origem natural, cujo curto período de proteção é compensado pela possibilidade de várias reaplicações. Após as análises realizadas neste gel-creme, conclui-se que apresentou um $\mathrm{pH}$ e viscosidade satisfatórios dentro do escopo estipulado para o produto, bem como, a análise de centrifugação realizada no Laboratório Industrial Farmacêutico Sobral. Ressalta-se a importância da realização de experimentos que comprovem o seu mecanismo de ação, toxicidade e os possíveis efeitos colaterais. Além do que, é necessário executar testes de estabilidade da formulação com vistas a garantir a sua qualidade e segurança.

PALAVRAS-CHAVE: planta citronela, repelente, gel-creme. 


\section{ANAIS DA XVII SEMANA DE ENFERMAGEM DA UESPI}

\section{REFERÊNCIAS}

${ }^{2}$ CRUZ, R. R. Estratégias para elcontrol del dengue e del Aedes aegypti em las Américas. Revista Cubana de Medicina Tropical, Havana 54(3): 189-201, 2002.

${ }^{1}$ FRADIN, M. $\quad$ S. Insect repellents. E-medicine. USA, 2002. (website: http://www.emedicine.com/derm/topic540.htm). Acesso 1 Novembro, 2016.

GIOPPO, C.; SILVA, R.V.; BARRA, V.M.M. A avaliação em ciências naturais no ensino fundamental. Curitiba: Ed. UFPR, 2006.

Ponzio HA. Guia de fotoproteção. São Paulo: Johnson \& Johnson; 15p. 2001.

3 Thavara, U; Tawatsin, A; Chansang, C; KongNgamsuk, W; Paosriwong, S; Boon-Long, J; et al. Larval occurrence, oviposition be havior and biting activity of potential mosquito vectors of dengue on Samui Island, Thailand. 2001

TUETUN, B.; CHOOCHOTE, W.; KANJANAPOTHI, D.; RATTANACHANPICHAI, E.; CHAITHONG，U.,CHAIWONG，P.; JITPAKDI，A.; TIPPAWANGKOSOL，P., RIYONG，D.; PITASAWAT, B. Comparative repellency of A. graveolens and commercial products. Tropical medicine \& international health: TM \& IH, Oxford, v. 10, n. 11,

p. 1190-1198 november, 2005. 


\section{ANAIS DA XVII SEMANA DE ENFERMAGEM DA UESPI}

\section{DINAMICA GRUPAL COMO ESTRATÉGIA TERAPÊUTICA EM UM CENTRO DE ATENÇÃO PSICOSSOCIAL}

Autores: Priscilla Souza Silva ${ }^{1}$, Ananda Carolina Barbosa da Silva ${ }^{2}$, Ana Caroliny de Barros Soares Lima ${ }^{3}$, Nanielle Silva Barbosa $^{4}$, Kauan Gustavo de Carvalho ${ }^{5}$, Lorena Uchoa Portela Veloso ${ }^{6}$. E-mail: priscillasouza740@gmail.com

Instituição: ${ }^{1}$ Universidade Estadual do Piauí, Floriano-PI, Brasil, ${ }^{6}$ Universidade Federal do Piauí, Teresina-PI, Brasil

Eixo temático: Temas livres

INTRODUÇÃO: Em oposição ao conceito manicomial, emerge a Reforma Psiquiátrica, modificando a assistência prestada, partindo da implementação de um novo modelo de prática na saúde mental (MOURA; FERREIRA; CARVALHO, 2012). Surgem, então, os Centros de Atenção Psicossocial (CAPS), espaço de referência e tratamento para pessoas que sofrem com transtornos mentais, destacando-se a psicoterapia de grupo como uma prática cada vez mais frequente dentro desses serviços por se tratar de uma estratégia de baixo custo e que não demanda grande quantitativo de insumos físicos para seu desenvolvimento (BRASIL, 2013). Possui flexibilidade de composição e aplicação, onde o mesmo instrumento pode ser utilizado por diferentes grupos, de formas distintas e almejarem o mesmo resultado, principalmente com conotações lúdicas que promovam a valorização da vida além de permitir a expressão por vias criativas e troca de saberes entre os participantes e os profissionais, demonstrando grande efetividade, pois possibilitam à expressão corporal, os relacionamentos interpessoais e a aproximação com a afetividade, comportamentos capazes de gerar mudanças na forma de se relacionar dos sujeitos (GUANAES; JAPUR, 2005; VALLADARES, 2003). OBJETIVO: Descrever o desenvolvimento de dinâmica grupal sobre valorização da vida como estratégia terapêutica no tratamento de transtornos mentais. MÉTODO: Estudo descritivo do tipo relato de experiência, vivenciado por acadêmicos de Enfermagem de uma universidade pública do estado do Piauí, desenvolvido em um CAPS do tipo II, na cidade de Teresina, que acompanha usuários em tratamento de transtornos mentais baseado em um plano terapêutico singular com o objetivo de reinseri-los no convívio familiar e comunitário. A atividade em grupo "Valorizando a vida" teve durabilidade entre 40 a 60 minutos em um ambiente destinado a encontros grupais, conhecido como "sala de grupo". Utilizaram-se balões cujo interior havia uma palavra, podendo ser: felicidade, amor, família, Deus, amizade, companheirismo, paz e CAPS. A atividade foi mediada pelos acadêmicos, de maneira a orientar e ajudar os participantes a expressarem suas opiniões. Após serem comunicados e convidados a participar da atividade, se reuniram em um grande círculo onde cada um escolheu um balão. Ao estourá-lo, devia expressar o que a palavra encontrada significava em sua vida. A partir de então, iniciou-se uma discussão aberta que contou com a participação de todos. RESULTADOS E DISCUSSÃO: As atividades em grupo do referido serviço acontecem de forma planejada, duas vezes por semana, às segundas e quartas, permitindo que tanto os usuários que frequentam diariamente o serviço, quanto os que comparecem apenas para a consulta médica, possam participar do momento de acolhimento. O ser humano, significante que é, 
entende-se e contextualiza-se na história, como uma pessoa ou um coletivo que tem sentimentos, pensamentos, e que, por meio deles, reflete sobre fatos, inventando formas de expressão, tornando possível as relações e os laços interpessoais (SOUSA; PINTO; JORGE, 2010; ARNDT; CUNHA; VOLPI, 2016). A primeira palavra a ser discutida foi felicidade. A resposta atribuída pelos participantes foi: 'felicidade é o que nasce no interior das pessoas", 'traz paz', '’é conhecer Deus e Jesus', 'saber o que é certo e o que é errado", 'fazer o bem", "'mostrar o que você sente'. Quando questionados sobre o significado e importância do CAPS, afirmaram que tiveram uma ótima oportunidade em poderem ser atendidos: 'foi muito bom ter conhecido', 'encontrei saúde e paz', 'segunda casa', 'onde fiz amizades", 'aprendi a pintar, desenhar, fazer atividade física, encontra os amigos, conversar com os pacientes", 'traz tranquilidade, relaxamento, fuga de problemas que eu tenho em casa'”. Consideraram que o CAPS seria um alicerce: 'a gente cai e o CAPS pega na nossa mão e faz ir além'. Pediu-se que todos falassem sobre o significado da palavra vida. Consideraram algo que une todos os sentimentos abordados: 'é ter saúde", '’é paz e amor", 'felicidade", 'união', 'harmonia', 'ter comida'. Ao término, como forma de conclusão da dinâmica em grupo, os participantes foram convidados a ouvir a letra da música Trem Bala. Ao final, os moderadores pediram que atribuíssem elogios à música: "'é muito bonita", 'fala de todos os sentimentos", fala de que devemos amar o que temos, nossos pais e filhos", "'devemos dar valor ao que temos", “' a vida passa muito rápido'. A psicoterapia em grupo almeja promover mudança no funcionamento psíquico. Proporcionar um espaço confiável e seguro para o paciente poder refletir com o terapeuta e com o restante do grupo. CONCLUSÃO: Considerando que haja certas limitações na estrutura do cuidado, perceber o grupo como uma ferramenta facilitadora da produção de novos sentidos pode contribuir para ampliar os repertórios interpretativos dos seus participantes. O que resulta em práticas mais saudáveis, mais inclusivas e promotoras de desenvolvimento psicológico e de valorização do meio em que se vive. A utilização das terapias grupais possibilita a atuação inter e multidisciplinar condizente com a prática clínica humana, equânime e resolutiva. Diante do exposto, o trabalho com grupos terapêuticos deve ganhar espaço nos serviços e instituições da rede de atenção à saúde, pois se trata de uma ação de importância significativa no planejamento de intervenções clínicas, apresentando resultados positivos no que se refere ao acompanhamento de diversos agravos e doenças no âmbito biopsicossocial.

PALAVRAS-CHAVE: Serviços de saúde mental, Psicoterapia de grupo, Saúde Mental.

\section{REFERENCIAS}

ARNDT, A. D.; CUNHA, R.; VOLPI, S. Aspectos da prática musicoterapêutica: contexto social e comunitário em perspectiva. Psicologia \& Sociedade, v. 28, n. 2, p. 387-95, 2016. 


\section{ANAIS DA XVII SEMANA DE ENFERMAGEM DA UESPI}

BRASIL. Ministério da Saúde. Secretaria de Atenção à Saúde. Departamento de Atenção Básica. Saúde mental. Departamento de Ações Programáticas Estratégicas. Cadernos de Atenção Básica (34). Brasília: Ministério da Saúde, 2013.

GUANAES, C.; JAPUR, M. Sentidos de doença mental em um grupo terapêutico e suas implicações. Psicol.: Teor. Pesqui., v. 21, n. 2, p.227-35, 2005.

MOURA, S. G.; FERREIRA, M. O. F.; CARVALHO, M. A. P. Evolução histórica da abordagem em saúde mental no Brasil: da reforma psiquiátrica aos dias atuais. Rev. enferm UFPE online. [Internet] v. 6, n. 3, 2012.

SOUSA, D. L. M; PINTO, A. G. A.; JORGE, M. S. B. Tecnologia das relações e o cuidado do outro nas abordagens terapêuticas grupais do centro de atenção psicossocial de fortaleza- ceará. Texto Contexto Enferm, v. 19, n. 1, p. 147-54, 2010.

VALLADARES, A. C. A. et al. Reabilitação psicossocial através das oficinas terapêuticas e/ou cooperativas sociais. Rev. Eletron. Enferm. v. 5, n. 1, p. 4-9, 2003. 


\section{ANAIS DA XVII SEMANA DE ENFERMAGEM DA UESPI}

\section{PREVALÊNCIA E FATORES RELACIONADOS AO COMPORTAMENTO SUICIDA ENTRE MINORIAS SEXUAIS}

Priscilla Souza Silva ${ }^{1}$, Ananda Carolina Barbosa da Silva ${ }^{2}$, Ana Caroliny de Barros Soares Lima ${ }^{3}$, Kauan Gustavo de Carvalho ${ }^{4}$, Nanielle Silva Barbosa ${ }^{5}$, Lorena Uchoa Portela Veloso ${ }^{6}$. E-mail: priscillasouza740@gmail.com

${ }^{1}$ Universidade Estadual do Piauí, Floriano-PI, Brasil, ${ }^{2,3,4,5}$ Universidade Estadual do Piauí, Teresina-PI, Brasil, ${ }^{6}$ Universidade Federal do Piauí, Teresina-PI, Brasil

Eixo temático: Temas livres

Modalidade de apresentação: Oral

Categoria: Estudantes e profissionais

INTRODUÇÃO: O suicídio é um ato intencional humano complexo e multifatorial que representa problema de saúde pública em todo o mundo. O comportamento suicida apresenta diversas manifestações associadas a pensamentos e atos autolesivos que são classificados em: ideação, plano, tentativa suicida e o suicídio propriamente dito. O suicídio mata mais que os homicídios e as guerras juntos, com uma estimativa anual de um milhão de óbitos, correspondendo cerca de $1,4 \%$ do total de mortes no mundo. O termo minorias sexuais engloba indivíduos que tem atrações sexuais/românticas pelo mesmo sexo ou de ambos os sexos, ou seja, aqueles que se identificam como Lésbicas, Gays, Bissexuais, Transgêneros, Transexuais, Travestis e Queer (LGBTQ). Estima-se que a taxa de tentativas suicidas entre os indivíduos LGBTQ é de 2 a 7 vezes maior do que o observado entre os heterossexuais. OBJETIVO: Analisar evidências científicas relacionadas à prevalência e fatores associados ao comportamento suicida em minorias sexuais. MÉTODO: Estudo de revisão integrativa da literatura, realizado nas bases de dados: Web of Science, MEDLINE/Pubmed, CINAHL e LILACS, realizado entre junho e julho de 2018, utilizando a estratégia PICo, onde atribuiu-se ao P: minorias sexuais, ao I: suicídio, ao Co: prevalência e fatores de riscos. RESULTADOS E DISCUSSÃO: Após serem submetidos aos critérios de inclusão e exclusão restaram 14 artigos para análise que foram publicados no período entre 2012 a 2018, com destaque para o ano de 2016 com 5 (35,7\%) publicações. Quanto ao local de pesquisa, houve predomínio da América do Norte com 9 (64,2\%). Ressalta-se que não foi encontrado nenhum artigo brasileiro em todas as etapas da pesquisa. Em relação ao delineamento do método, abordagem metodológica mais frequente foi o estudo de coorte com $8(57,1 \%)$ e as amostras dos estudos variaram de 68 a 146621 participantes. Quanto ao nível de evidências observou-se que o nível 2B prevaleceu com 8 (57,1\%) publicações. A extração das informações facilitou a construção de duas categorias temáticas: prevalência do comportamento suicida e fatores associados ao comportamento suicida. A prevalência de ideação suicida na população LGBTQ variou de $22 \%$ a $67 \%$, enquanto que na população geral citadas nos estudos variou de 3,48\% a 23,8\%. Tais dados corroboram com estudo realizado nos Estados Unidos, onde as minorias sexuais obtiveram 3.76 mais chances de ideação suicida quando comparada com população 


\section{ANAIS DA XVII SEMANA DE ENFERMAGEM DA UESPI}

geral. A população LGBTQ mais prevalente em relação a ideação suicida e tentativa foi a transexual com uma taxa de $67 \%$ e $35,5 \%$ respectivamente e a menor foi em homossexuais com $22 \%$ para ideação e $17 \%$ para tentativas. Vários estudos apontam que jovens transgêneros são mais vulneráveis ao abuso de gênero, fator que estaria associado esse comportamento. Em relação ao sexo masculino, os homens gays foram mais propensos a relatar tentativa de suicídio nos últimos 12 meses do que homens heterossexuais, onde as mulheres de forma geral relatam mais tentativas do que os homens. Embora o sexo feminino seja duas vezes mais provável relatar tentativas suicidas do que o sexo masculino, estes têm mais êxitos nas tentativas, logo maiores números de suicídios consumados, cerca de 3 a 5 vezes maiores que ela. Os fatores associados são definidos como características, situações, ou circunstâncias que tem algum impacto na saúde de uma população, ou seja, são traços significativos para predisposição ou na proteção de determinada situação. As minorias sexuais, assim como a população em geral possuem fatores riscos e de proteção para comportamento suicida semelhantes que seriam, por exemplo, a depressão, o uso de substâncias psicoativas, insegurança escolar e suporte inadequado, seja familiar ou social. Em relação aos fatores de riscos o que mais se destacou foi a discriminação citada em 10 artigos (71,4\%). Os comportamentos discriminatórios sofridos por jovens de minorias sexuais podem aumentar o risco de depressão e consequentemente o comportamento suicida. Entre os fatores protetores que tiveram mais predomínio foram apoio social com $10(71,4 \%)$ dos artigos. O apoio social é essencial na proteção contra as ameaças externas, visto que a maioria das minorias sexuais sofrerem os mais altos níveis de violência, incluindo abuso sexual e físico, quando em comparados com a população heterossexual. Embora não apontado em muitos artigos, cabe destacar o reconhecimento da identidade de gênero nos documentos oficiais como fator protetor para o comportamento suicida. CONCLUSÃO: Percebe-se que as minorias sexuais são mais propensas ao comportamento suicida comparadas a população geral, com destaque a população transexual que apresenta maiores prevalências. Em relação aos fatores de riscos a discriminação foi a que obteve o maior impacto para esse comportamento. Além, do apoio social e familiar considerados fatores protetores para diminuir essa prevalência. Tais dados apontam para uma necessária reflexão das políticas de prevenção do comportamento nesse grupo específico, que possam incluir estratégias adequadas aos fatores de risco e protetores identificados. Melhorando os métodos de triagem e fortalecendo a promoção de qualidade de vida; além de informar e sensibilizar a sociedade de que o suicídio é um problema de saúde pública que pode ser prevenido, muitas vezes com a identificação dos fatores de riscos, com intuito de reduzir a morbimortalidade dessa população vulnerável.

PALAVRAS-CHAVE: Pessoas LGBT, Suicídio, Prevalência e Fatores de Riscos. 


\section{ANAIS DA XVII SEMANA DE ENFERMAGEM DA UESPI}

\section{REFERENCIAS}

BAUER, G. R. et al. Intervenable factors associated with suicide risk in transgender persons: a respondent driven sampling study in Ontario, Canada. Rev. BMC Public Health. V. 15, n. 2, 2015.

BERGERON, F. A.; BLAIS, M. I.; HÉBERT, M. The role of parental support in the relationship between homophobic bullying, internalized homophobia and psychological distress among sexual-minority youths (SMY): a moderated mediation approach. Rev. Sante Ment Que. v. 40, n.3, 2015.

TERADA, S. et al. Suicidal ideation among patients with gender identity disorder. Rev. Psychiatry Res. v. 190, n. 1, 2011.

WHO. World Health Organization. Suicide prevention. Department of Mental Health. Geneva, [Internet]. $2014 \quad$ [citado $2017 \quad \mathrm{dez} \quad$ 17] Available from: http://www.who.int/mental_health/prevention/suicide/suicideprevent/es/index.html.

WOODHEAD, C. et al. Mental health among UK inner city non-heterosexuals: The role of risk factors, protective factors and place. Rev. Epidemiology and Psychiatric Sciences. v. 25, n. 5, 2016. 


\section{ANAIS DA XVII SEMANA DE ENFERMAGEM DA UESPI}

\section{FATORES ASSOCIADOS A NÃO ADESÃO AO EXAME CITOPATOLÓGICO}

$\underline{\text { Daiane Magalhães Silva }}^{1}$ Alessandra dos Santos de Araújo Rodrigues ${ }^{1}$, Ianny Soares de Carvalho ${ }^{1}$, Joana Beatriz de Lima Silva', Maria Luzinete Rodrigues da Silva'. E-mail: daiane_magalhaes22@hotmail.com

${ }^{1}$ Universidade Estadual do Piauí - UESPI, Floriano-PI, Brasil.

Eixo Temática: Enfermagem no processo saúde-doença.

INTRODUÇÃO: O câncer de colo uterino (CCU) constitui um grave problema de saúde que atinge mulheres em todo o mundo [...], porém, os países em desenvolvimento são responsáveis por 80\% desses casos. Mediante o Instituto Nacional do Câncer - INCA, (2018), no Brasil, 16.370 casos novos de câncer do colo do útero para o ano de 2018 a 2019, com um risco estimado de 15,43 casos a cada 100 mil mulheres. De acordo com Oliveira et al (2016), o exame citopatológico é o método padrão para rastreamento do Câncer de Colo do Útero, por ser uma técnica efetiva e eficiente, diminuindo as taxas de morbimortalidade, não obstante, a taxa de cobertura é insuficiente devido a fatores socioeconômicos, culturais, sexuais e reprodutivos, além dos fatores relativos à assistência em saúde. OBJETIVO: Analisar na literatura os fatores responsáveis a não adesão ao exame citopatológico. MÉTODO: Trata-se de um estudo revisão bibliográfica caracterizado pelas leituras e pesquisas com contribuições cientificas e culturais a respeito do tema abordado. Onde foram realizadas buscas por produções cientificas em bancos de dados virtuais como Google Acadêmico e Scientific Electronic Library Online (SCIELO), tendo como questão norteadora: quais os principais fatores de não adesão ao exame citopatológico? Utilizando os descritores: não adesão, fatores, mulheres, exame citopatologico, Brasil. O critério para seleção foram artigos publicados na integra, em português entre os anos de 2015 a 2018 relacionados a temática do estudo, obrigatoriamente foram excluídos os artigos fora do recorte temporal e que não correspondiam ao tema. O período das revisões compreendeu- se os meses de março a abril de 2019. Foram selecionados 08 artigos, dos quais foram feitos leituras e estudos. RESULTADOS E DISCUSSÃO: Os estudos encontrados mostraram três principais categorias como pilar para a não adesão ao referido exame: Sentimentos que interferem na não adesão; Falta de conhecimento sobre o exame; e Dificuldade no gerenciamento do serviço referente ao exame. Na primeira categoria, os sentimentos mais relatados foram a vergonha, o medo e o desconforto, estando presentes em 100\% dos artigos. Sendo a vergonha o fator de maior expressividade dentre estes. Segundo Sampaio et al citado por Costa; Silva; Souza (2018) o gênero do profissional do sexo masculino é uma forte influência para a não adesão ao exame citopatológico, visto que muitas mulheres referiram vergonha e medo ao ser examinadas por profissionais desse gênero. Na segunda categoria, foi possível perceber que a falta de conhecimento está atrelada indubitavelmente aos fatores de não adesão ao exame citopatológico, dentre os artigos abordados para o 


\section{ANAIS DA XVII SEMANA DE ENFERMAGEM DA UESPI}

estudo, 37,05\%, apontaram que as mulheres não sabiam o real objetivo do exame, tornando um público mais propício ao desenvolvimento do câncer de colo do útero. De acordo com Barbosa et.al (2017), o profissional de saúde possui um papel fundamental em relação à prevenção, necessitando desempenhar um papel de educador, trabalhando os fatores que ainda influenciam as mulheres no seu autocuidado. Dessa forma, fica entendido que todos os profissionais de saúde devem orientar sobre a relevância do exame preventivo, pois a sua periodicidade permite diminuir o índice de mortalidade por câncer do colo do útero nas mulheres. Na terceira categoria, foi observado que a falta de materiais e a dificuldade no agendamento e no recebimento dos exames, visto que, dos artigos agregados a este estudo 37,05\% referenciaram estes itens supracitados como causas para a não realização do exame. Assim, fazendo referência a Barbosa et al (2017) há dificuldades que interferem na cobertura do exame citopatológico pelas Unidades Básica de Saúde dificultando a acessibilidade das mulheres a submeterem ao exame preventivo. Outro fato importante, segundo Silva et al (2015), é a organização dos serviços de Atenção Primária que não se adequa a rotina das mulheres atuante no mercado de trabalho, pois sabe-se que o funcionamento dos estabelecimentos vai de desencontro com as atividades trabalhistas exercidas por este público fazendo com que isso seja um dos motivos para a não adesão ao exame. Seguindo o estudo de Recanello; Sousa; Dias (2017) fatores como estes já citados dificultam o objetivo principal do exame que é prevenir o câncer de colo de útero. Dessa forma, a mulher deixa de ser assistida previamente, fazendo com que muitas descubram tardiamente as possíveis alterações. CONCLUSÃO: Tendo em vista que o câncer de colo uterino atinge um número expressivo de mulheres em todo o mundo e que a principal estratégia para prevenção é o exame citopatológico, tem que haver estratégias que facilitem a assistência desse público alvo, como: enfatizar a educação em saúde, tentar estabelecer vínculos de confiança entre paciente e profissional. Quanto as organizações dos serviços estas devem estar estruturadas com base no modo de vida das mulheres buscando formas para que estas tenham uma maior acessibilidade ao serviço. Assim sendo, esse estudo aborda a necessidade de mais investigações sobre o tema, abrindo precedentes para mais estudos sobre tal temática, corroborando com ações que facilitem a adesão das mulheres ao exame citopatológico.

PALAVRAS-CHAVE: Exame citopatológico, não adesão, Câncer do colo do útero.

\section{REFERENCIAS:}

BARBOSA, C,R. SILVA, L,M,A. SILVA, C,A. COSTA, D,J,S,F. SANTOS, L, R SANTOS, N, R. Percepção de mulheres sobre os fatores associados a não realização do exame papanicolau. Interfaces Científicas - Saúde e Ambiente. Aracaju. V.5. N.3. p.87 - 96 . Jun. 2017. Disponível em: <https://periodicos.set.edu.br/index.php/saude/article/view/2917/pdf>. Acesso em: 09 de maio de 2019. 


\section{ANAIS DA XVII SEMANA DE ENFERMAGEM DA UESPI}

COSTA, R, S, L. SILVA, M, V, R. SOUZA, T, N. Fatores que levam a não adesão ao exame preventivo do câncer do colo uterino em uma unidade de saúde do acre em 2014. Revista DêCiência $\begin{array}{llllll}\text { em } & \text { Foco. } & \text { V.2 } & \text { N.2. } & 2018 & \text { Disponível }\end{array}$ <http://revistas.uninorteac.com.br/index.php/DeCienciaemFoco0/article/view/207/55> Acesso em: 09 de abril de 2019.

MINISTÉRIO DA SAÚDE, Instituto Nacional de Câncer José Alencar Gomes da Silva. Estimativa do câncer. Rio de Janeiro, 2018. Disponível em: < http://www1.inca.gov.br/estimativa/2018/estimativa2018.pdf> Acesso em: 07 de abril de 2019.

OLIVEIRA, A, E, C. DEININGER, L, S, C. LIMA, I, M, B. LIMA, D, C. DO NASCIMENTO, J, A. ANDRADE, J, M. Adesão das mulheres ao exame citológico do colo uterino na atenção básica.

Disponível em: $<\mathrm{http}$ ///bases.bireme.br/cgibin/wxislind.exe/iah/online/?IsisScript=iah/iah.xis\&src=google \&base=BDE NF\&lang=p\&nextAction=lnk\&exprSearch=30146\&indexSearch=ID>Acesso em: 09 de abril de 2019.

RECANELLO, C. SOUZA, E,S,M. DIAS, M,K,S. Fatores que influenciam na não adesão ao exame citopatologico: percepção das mulheres. 2018, 8 p. Trabalho de Conclusão de Curso apresentado a: UNIVAG, Curso GPA ciências da saúde, Enfermagem Disponível em: <http://www.repositoriodigital.univag.com.br/index.php/enf/article/view/31/31>. Acesso em: 03 de março de 2019.

SILVA, M,A,S. TEIXEIRA, E,M,B. FERRARI, R,A,P. CESTARI, M,E,W. CARDELLI, A,A,M. Fatores relacionados a não adesão à realização do exame de Papanicolau. Revista Rene jul-agos. 2015 Disponível em: <https://www.redalyc.org/html/3240/324041519010/ > Acesso em: 25 de abril de 2019. 


\section{ANAIS DA XVII SEMANA DE ENFERMAGEM DA UESPI}

\section{RELUTÂNCIA DO HOMEM NA ASSISTÊNCIA PRIMÁRIA A SAÚDE: REVISÃO INTEGRATIVA}

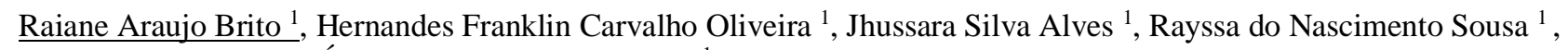
Államy Danilo Moura e Silva1. E-mail: raiane_araujobrito@hotmail.com

${ }^{1}$ Universidade Estadual do Piauí - UESPI, Floriano - PI, Brasil

Área temática: Temas livres

INTRODUÇÃO: A população masculina apresenta resistência quando se trata de cuidados com a saúde, em especial no que se diz respeito ao ato preventivo, e isto está ligado a uma série de "tabus", que já vem enraizado na cultura masculina. O número de letalidade relacionado ao gênero masculino é bem maior do que o feminino ao longo da vida. O homem não pratica hábitos saudáveis de vida, consequentemente não procura os serviços de saúde, isso pode estar ligado à historicidade do homem contemporâneo. A não acessão dos homens aos serviços de saúde é um desafio para a enfermagem. Com a finalidade de organizar e realizar diretrizes e ações voltadas para a promoção, prevenção da saúde e melhoria de vida, foi instituída a PNAISH- Política Nacional de Atenção Integral à Saúde do Homem. OBJETIVO: Identificar as barreiras que distanciam os homens do cuidado preventivo da saúde na atenção básica. MÉTODOS: Trata-se de uma revisão integrativa da literatura, realizada no banco de dados da Biblioteca Virtual em Saúde (BVS), no período de abril a maio de 2019. A consulta atendeu ao critério da presença dos Descritores em Ciências da Saúde (DeCS): Saúde do Homem, Atenção Primária à Saúde e Política de Saúde (PNAISH), que direcionaram para 97 artigos. Para nortear este estudo foram incluídos textos completos disponíveis que comtemplam a temática e excluídos as resenhas, as monografias, os artigos apresentados em congressos e conferências e publicações em outros idiomas. Para a seleção dos artigos, foram analisadas quanto aos critérios de inclusão: publicados entre 2015 e 2018, disponíveis gratuitamente, cujos objetivos condiziam com a temática desse estudo. Destes, 14 foram escolhidos para serem lidos na íntegra. RESULTADOS E DISCUSSÃO: Este estudo foi fundamentado a partir de referências bibliográficas que nortearam o trabalho, evidenciando os desafios enfrentados na implementação de políticas públicas voltadas a saúde do homem que podem ser classificados em duas classes: a primeira refere-se ao gênero masculino e a busca dos serviços de saúde e a segunda é pertinente ao profissional de Enfermagem e relacionada à sua formação. Alves et al., (2017) fomenta no que se refere ao gênero masculino, a razão primordial pela qual os homens não procuram os serviços de saúde é devido ao ponto de vista masculino de que o cuidado com o corpo é algo exclusivo das mulheres, e tal conduta está atrelada às demandas dos mesmos no que diz respeito ao seu trabalho, que vem a dificultar o seu ingresso 
às unidades básicas de saúde, atribuído ao tempo perdido nas filas para a marcação de consulta. Já Pereira e Barros (2015), em pesquisa realizada em uma unidade básica de saúde (UBS), constatou que: A baixa frequência de homens no serviço é atribuída à resistência por parte deles, não sendo reconhecida sua inclusão no atendimento e nas ações educativas ou comunitárias do programa como uma questão da estratégia e proposta assistencial. O não comparecimento do homem nas unidades básicas de saúde não está conectada apenas às suas características de identidade ou ao seu déficit de autocuidado, estando atrelada também à desorganização do modelo assistencial da atenção primaria à saúde. Em outra literatura, é afirmado que as ações preventivas são dirigidas quase exclusivamente às mulheres, limitando a assistência aos homens à dimensão curativa da atenção. Observou-se falha na capacitação e no conhecimento científico dos enfermeiros em relação à PNAISH, foram evidenciados que os enfermeiros tinham um conhecimento principiante sobre a saúde do homem. Portanto, não desenvolviam ações de assistência nas UBS específicas para os homens, preocupando-se em possibilitar cuidados com populações consideradas mais vulneráveis, como idosos, crianças e mulheres. Constatou-se também que os enfermeiros não recebem treinamento nesta área. Desse modo, enfatiza-se a necessidade de qualificação e capacitação profissional permanente para promover a PNAISH, pois o enfermeiro capacitado tem a possibilidade de desenvolver estratégias para que o homem possa estar mais presente nos serviços (ALVES et al., 2017). Dessa forma, a precária instrução dos profissionais sobre essa política, valida a possível inexistência de capacitações acerca da saúde do homem, o que intervém diretamente na assistência. Além da necessidade de capacitação, nota-se a importância de os enfermeiros buscarem o conhecimento científico e se responsabilizarem pela sua educação permanente. Portanto, destaca-se a necessidade de os enfermeiros irem em busca da qualificação e aprimoramento técnico, pois a formação permanente dos profissionais é um dos fatores essenciais no sucesso do atendimento e eficácia dos serviços de saúde (SILVA et al., 2015). Verificaram que, na maioria das vezes são realizadas ações não direcionadas especificamente ao homem, desconsiderando as reais necessidades desse público-alvo e tampouco os indicadores de saúde referenciados na PNAISH (ASSIS et al 2018). Os autores Pereira e Barros (2015) destacam ainda, que se faz necessário um programa de educação continuada que qualifique e capacite os profissionais sobre a PNAISH, pois possibilitará a implementação eficaz da mencionada política sendo que a ausência de capacitação e instrumentos metodológicos impedem que os profissionais tenham habilidades para realizar o atendimento ao homem. CONCLUSÃO: Diante do exposto, evidencia-se a relutância dos homens na assistência primária à saúde, e permitiu verificar a relevância do enfermeiro como membro essencial na atenção primária. Observou-se também que no processo de trabalho do enfermeiro há significativas fragilidades concernentes ao conhecimento e à efetivação da PNAISH. Considera-se 


\section{ANAIS DA XVII SEMANA DE ENFERMAGEM DA UESPI}

relevante a implementação de políticas públicas, com proventos de favorecer a qualidade de vida e aumento do nível de conhecimentos dos homens quanto a importância do autocuidado e prevenção de doenças, assim como, fomento e ações de educação permanente dos enfermeiros para atuação no cuidado integral à saúde do homem.

Palavras-chave: Saúde do homem, Atenção Primária à Saúde, Enfermagem.

\section{REFERÊNCIAS}

ALVES, Bruna Michelle de Souza; ARAÚJO, Cássia Juliana da Silva; ALMEIDA, Simone Lugon da Silva; GUIMARÃES, Aline Luzia Sampaio. Atuação do enfermeiro da atenção básica diante das dificuldades para a implementação da política de saúde do homem. Revista de Enfermagem-UFPE. Recife, 11(Supl. 12):5391-401, dez., 2017. Disponível em < https://doi.org/10.5205/1981-8963v11i12a110143p5391-5401-2017>. Acessado em 25 de abril.

ASSIS, Natália; O. de; RODRIGUES, Juliana; CHRISTÓFORO, Berendina Elsina Bouwman; TACSI, Yolanda Rufina Condorimay. Atuação dos enfermeiros frente à política nacional de atenção integral a saúde do homem: um estudo exploratório. Arquivo de Ciência de Saúde da UNIPAR. Umuarama, v. 22, n. 3, p, 151-156, set. /dez. 2018. Disponível em < https://doi.org/10.25110/arqsaude.v22i3.2018.6397>. Acessado em 25 de abril.

PAIVA, Jáder Ferreira Leite; PAIVA, Rafael; AMORIM, Ana Karenina de Melo Arraes. DIMENSTEIN, Magda; CARVALHO, Lúcia. FRANÇA, Aparecida. Sentidos da Saúde numa Perspectiva de Gênero: um Estudo com Homens da Cidade de Natal/RN. Psicologia: Ciência e Profissão. Abr./jun. 2016 v. 36 n², 341-353. Disponível em < 10.1590/1982-3703001812013>. Acessado em 25 de abril.

PEREIRA, Mayara Carneiro Alves; BARROS, João Paulo Pereira. Públicos masculinos na estratégia de saúde da Família: estudo qualitativo em parnaíba-pi. Psicologia \& Sociedade. 2015. Disponível em http://dx.doi.org/10.1590/1807-03102015v27n3p587. Acessado em 25 de abril.

SILVA, Júlio César Santos da; VASCONCELOS, Suzy Darlen Dutra de, SANTOS, Úrsula Pérsia Paulo dos; FERREIRA, Marcela dos Santos, COELHO, Maria José. Avaliação do nível de conhecimento sobre a saúde do homem: contribuições para a prática assistencial no nível técnico em enfermagem. REUFPI Revista de Enfermagem da UFPI. 2015 Jul-Sep;4(3):54-8. Disponível em ISSN:2238-7234. Acessado em 25 de abril. 


\section{ANAIS DA XVII SEMANA DE ENFERMAGEM DA UESPI}

\section{RESUMOS MODALIDADE PÔSTER}




\section{ANAIS DA XVII SEMANA DE ENFERMAGEM DA UESPI}

\section{A IMPORTÂNCIA DA ANAMNESE E EXAME FÍSICO REALIZADO PELA ENFERMAGEM A PACIENTES HOSPITALIZADOS: RELATO DE EXPERIÊNCIA}

$\underline{\text { Sueli de Sousa Estrela Araújo }}^{1}$, Suzana Honória de Sousa ${ }^{1}$, Arturgesina Martins Vasconcelos Lima ${ }^{1}$, Maraisa Piauilino de Lima $^{1}$, Elusiany Sousa Silva ${ }^{1}$, Maria Luzinete Rodrigues da Silva ${ }^{1}$. E-mail: suelyestrela@ hotmail.com

${ }^{1}$ Universidade Estadual do Piauí - UESPI, Floriano-PI, Brasil

Eixo temático: Enfermagem no Processo Saúde/Doença

INTRODUÇÃO: A anamnese e o exame físico representam um instrumento de grande valia para a assistência, uma vez que permite ao enfermeiro realizar o diagnóstico, planejar ações de enfermagem, acompanhar e avaliar a evolução do paciente. Na realização do exame físico, os recursos utilizados são os métodos propedêuticos, que estabelece na inspeção; palpação; percussão e ausculta. O processo de enfermagem tem representado um principal modelo metodológico para o desempenho sistemático da prática profissional, onde favorece métodos para organizar as condições necessárias na realização da assistência e registrar a prática profissional. OBJETIVO: Descrever experiência relacionada à importância da anamnese e exame físico a pacientes hospitalizados. MÉTODOS: Trata-se de um relato de experiência, de caráter descritivo, realizado pelas alunas do curso de Bacharelado em Enfermagem do IX período da Universidade Estadual do Piauí-UESPI, vivenciado em um hospital público no município de Floriano-PI, no período de março e abril de 2019. As práticas foram aplicadas a partir de medidas assistenciais, orientações e análise temática do conteúdo observado. RESULTADOS: As observações das graduandas acerca da utilidade do processo inerente em relação à anamnese e exame físico realizado pela enfermagem permitiu perceber a importância da avaliação organizada, e reconhecer que esses processos são capazes de estabelecer a relação julgamento-intervenção-avaliação intrínseca ao desenvolvimento assistencial para promover cuidados adequados de acordo com as necessidades específicas do cliente. Foi possível identificar que esses fatores requerem do profissional de enfermagem um olhar além da condição de adoecimento uma visão holística em que os mesmos estejam atentos primordialmente à pessoa e suas reais necessidades. Percebeu-se o déficit na aplicação da Sistematização da Assistência de Enfermagem-SAE e Processo de Enfermagem-PE, sendo que são de extrema importância que se realize estas ações regularmente sempre nos horários prescritos ou de acordo com a necessidade do cliente. CONCLUSÃO: O referenciado trabalho permitiu compreender a aplicabilidade da Sistematização da Assistência de Enfermagem-SAE e Processo de Enfermagem-PE através do exame físico possibilitando a eficácia na evolução clínica na qual representa um importante instrumento para as informações colhidas. Sendo que sua execução é uma fase essencial que deve ser exercido de forma 


\section{ANAIS DA XVII SEMANA DE ENFERMAGEM DA UESPI}

criteriosa pelos enfermeiros e desenvolvido de forma teórico/prático, portanto é feito no sentido céfalocaudal e torna-se necessário conhecimento científico do profissional para a execução dessas atividades.

PALAVRAS-CHAVE: Anamnese, Exame Físico, Assistência em Enfermagem.

\section{REFERÊNCIAS}

TANNURE, Meire Chucre. SAE: Sistematização da Assistência de Enfermagem: Guia Prático / Meire Chucre Tannure, Ana Maria Pinheiro. 2. Ed. - [Reimpr.] - Rio de Janeiro: Guanabara Koogan, 2011.

SANTOS, N; VEIGA, P; ANDRADE, R. Importância da anamnese e do exame físico para o cuidado do enfermeiro. Revista. Brasileira. Enfermagem, v. 64, n. 2, p. 355-358. Brasília. Apr. 2011.

SILVA, V; LIMA, D.V.M; FULY, P.S.C. Instrumento para a realização de exame físico: contribuindo para o ensino em enfermagem. Escola Anna Nery, v. 16, n. 3, p. 514-522., Rio de Janeiro. Setembro, 2012.

COFEN. Resolução No 358 de 15 de outubro de 2009. Dispõe sobre a Sistematização da Assistência de Enfermagem e a implementação do Processo de Enfermagem / COFEN -Conselho Federal de Enfermagem. Brasília-DF. 


\section{A PERSPECTIVA PRÁTICA E A LIDERANÇA EM ENFERMAGEM: REVISÃO DE LITERATURA}

Maraisa Piauilino de Lima ${ }^{1}$, Suzana Honória de Sousa ${ }^{1}$, Arturgesina Martins Vasconcelos Lima ${ }^{1}$, Sueli de Sousa Estrela Araújo $^{1}$, Elusiany Sousa Silva ${ }^{1}$, Maria Luzinete Rodrigues da Silva ${ }^{1}$. E-mail: maraisapiauilino@ gmail.com

${ }^{1}$ Universidade Estadual do Piauí - UESPI, Floriano-PI, Brasil

Eixo temático: Boas Práticas de Enfermagem na Assistência, Ensino, Pesquisa e Gestão

INTRODUÇÃO: Define-se liderança a influência de um líder em relação aos seus adeptos com um olhar ao alcance de seus ideais sempre alinhados em concordâncias com o nível cultural e organizacional de suas competências, sendo estas características indispensáveis ao profissional enfermeiro. Contudo desde os tempos de Florence, a preocupação da enfermagem foi à qualidade do serviço, da mesma forma nos dias atuais e principalmente com a tecnologia, essa profissão tem se desenvolvido com um olhar voltado para o cuidado através de avaliações de todo o processo estrutural que compõem a assistência. OBJETIVO: Refletir sobre a perspectiva prática e a liderança em enfermagem. MÉTODOS: Realizouse o levantamento através de revisão de literatura, do tipo qualitativa, a partir de pesquisa realizada na Biblioteca Virtual em Saúde (BVS), no período de abril de 2019. Para a busca, utilizou-se os descritores: Liderança em Enfermagem e Gestão em Enfermagem. Em seguida, a partir dos critérios de inclusão: ano de publicação 2015 a 2018; texto completo; tipo de documento artigo; resultaram 454 artigos. Logo após, foram excluídos os artigos repetidos, artigos em idiomas inglês e espanhol e que não contemplassem com a temática abordada, restando 14 artigos para análise de elaboração deste estudo, mas depois dessa seleção restaram para a organização final 3 artigos. RESULTADOS: Os conhecimentos gerenciais do enfermeiro, abrange auditoria, resolução, elaboração de um complexo processo que envolve o exercício da profissão, dessa maneira a liderança cada vez mais exige capacitação que se inicia na academia necessitando de aprimoramento e organização, as práticas gerenciais devem ser contínuas e atualizadas durante a vida profissional. É evidente que por meio da liderança o enfermeiro realiza suas atividades contribuindo de forma singular na assistência ao paciente, essa autonomia atribuída ao enfermeiro na tomada de decisões dentro da instituição proporciona um vínculo facilitador entre os objetivos da instituição, a equipe de enfermagem e a assistência realizada pelo enfermeiro que exerce a liderança. CONCLUSÃO: O presente trabalho evidencia a importância da formação acadêmica e da relação social, no âmbito da liderança com objetivo de identificar e aprimorar as competências, no contexto atual, o exercício de liderança tem se tornado cada vez mais significativo devido à complexidade que envolve o ambiente de atuação que esse profissional está inserido. Ressaltando a relevância em pesquisas atuais 


\section{ANAIS DA XVII SEMANA DE ENFERMAGEM DA UESPI}

que capacite à prática profissional em virtude dos frequentes desafios enfrentados pelo enfermeiro em seu ambiente profissional.

PALAVRAS-CHAVE: Liderança em Enfermagem, Enfermeiro, Gestão em Saúde.

\section{REFERÊNCIAS:}

NEVES, Vanessa Ribeiro; SANNA, Maria Cristina. Conceitos e práticas de ensino e exercício da liderança em Enfermagem/ Revista Brasileira de Enfermagem. [Internet].2016;69(4):686-93. Disponível em: \&lt;http://dx.doi.org/10.1590/0034-7167.2016690417i\&gt;. Acesso em 25 de abril de 2019.

SOARES, Mirelle Inácio; CAMELO, Silvia Helena Henriques; RESCK, Zélia Marilda Rodrigues; TERRA, Fábio de Sousa. Saberes gerenciais do enfermeiro no contexto hospitalar. Revista Brasileira de Enfermagem [Internet]. 2016;69(4):631-7. Disponível em: \&lt;http://dx.doi.org/10.1590/00347167.2016690409i\&gt;. Acesso em 25 de abril de 2019.

SOBRINHO, Aline Bezerra; BERNARDO, Juliana Maria Silva; ALEXANDRE, Ana Carla Silva; LEITE-SALGUEIRO, Cláudia Daniele Barros; OLIVEIRA, Valdeilson Lima de Oliveira. Liderança do Enfermeiro: Reflexões Sobre o Papel do Enfermeiro no Contexto Hospitalar. Id on Line Revista Multidisciplinar de Psicologia. V.12, N. 41, p. 693-710, 2018. Disponível em: \&lt;http://idonline.emnuvens.com.br/id\&gt;. Acesso em 26 de abril de 2019. 


\section{ASSISTÊNCIA DE ENFERMAGEM AO PACIENTE NO PÓS-OPERATÓRIO DE PROSTATECTOMIA: RELATO DE EXPERIÊNCIA}

Arturgesina Martins Vasconcelos Lima ${ }^{1}$, Suzana Honória de Sousa ${ }^{1}$, Conceição de Maria Vasconcelos Alves ${ }^{1}$, Sueli de Sousa Estrela Araújo ${ }^{1}$, Elusiany Sousa da Silva ${ }^{1}$, Maria Luzinete Luzinete Rodrigues da Silva ${ }^{1}$ :

${ }^{1}$ Universidade Estadual do Piauí - UESPI, Floriano-PI, Brasil

Eixo Temático: Enfermagem no Processo Saúde/Doença.

INTRODUÇÃO: O câncer de próstata é caracterizado pelo desenvolvimento do tumor em qualquer parte da glândula, sendo a segunda maior causa de morte por câncer do gênero masculino no Brasil, com uma taxa anual de 12 óbitos por 100.000 homens. Quando a patologia é suficientemente grande para ultrapassar os limites do colo e da bexiga, os sinais e sintomas de obstrução podem ocorrer, tais como dificuldade e frequência da micção, retenção urinária, tamanho e força do jato urinário diminuído. OBJETIVO: Discorrer a assistência de enfermagem ao paciente no pós-operatório de prostatectomia. MÉTODOS: Trata-se de um relato de experiência realizado por acadêmicas do curso de enfermagem do IX período da Universidade Estadual do Piauí-UESPI, de caráter exploratório, desenvolvido a partir do acompanhamento e observação ao paciente no pós-operatório de prostatectomia em um hospital público de referência no município de Floriano-PI, nos meses de março e abril de 2019. A execução do estudo foi a partir da assistência a um paciente, e paralelamente através de embasamentos teóricos sobre o procedimento, bem como seu tratamento e intervenções necessárias. RESULTADOS: Esse estudo teve grande relevância na recuperação do paciente através de assistência de enfermagem, de modo a permitir uma avaliação contínua para prevenir complicações advindas da patologia e estabelecer medidas de enfrentamento da doença e consequentemente melhoria no quadro clínico. A realização da assistência se deu a partir dos registros nos prontuários, como histórico e exame físico do paciente. Os diagnósticos identificados foram: eliminações urinárias prejudicadas; risco de infecção; ansiedade e mobilidade física prejudicada. Sobre o tratamento, além de medidas farmacológicas foi também prestado esclarecimentos e técnicas para ajudar controlar a ansiedade. A assistência de enfermagem foi baseada no cuidado e nas necessidades do paciente, objetivando a medida curativa, enfrentamento da doença e o autocuidado. Essas ações possibilitaram a melhoria da condição de saúde do cliente, com melhora significativa tanto clínica como psicológica, nessa condição obteve alta hospitalar com orientações ao acompanhamento e cuidados domiciliares. CONCLUSÃO: O desenvolvimento do estudo realizado permitiu reportar um conhecimento acerca do câncer de próstata, assim como prestar uma assistência de enfermagem e acompanhamento ao paciente oncológico hospitalizado, bem como as principais complicações em decorrência do processo cirúrgico. Contudo a aplicabilidade da Sistematização da Assistência de 


\section{ANAIS DA XVII SEMANA DE ENFERMAGEM DA UESPI}

Enfermagem - SAE, torna-se necessária para o profissional enfermeiro na identificação dos problemas e tomar medidas intervencionistas relacionadas ao cuidado individual e coletivo.

PALAVRAS-CHAVE: Câncer de Próstata, Assistência de Enfermagem, Oncologia.

\section{REFERÊNCIAS}

BRASIL. Ministério da Saúde. Secretaria de Atenção à Saúde. Departamento de Atenção Básica. Caderno de atenção primária: Rastreamento / Ministério da Saúde, Secretaria de Atenção à Saúde, Departamento de Atenção Básica. - Brasília: Ministério da Saúde, 2010.

Brunner \&amp; Suddarth. Manual de enfermagem médico-cirúrgica / revisão técnica Sonia Regina de Souza; tradução Patricia Lydie Voeux. - 13. ed. - Rio de Janeiro: Guanabara Koogan, 2015.

Diagnósticos de Enfermagem da NANDA-I: definições e classificação 2018-2020 [recurso eletrônico] / [NANDA International]; tradução: Regina Machado Garcez; revisão técnica: Alba Lucia Bottura Leite de Barros... [et al.]. - 11. ed. - Porto Alegre: Artmed, 2018. 


\section{ANAIS DA XVII SEMANA DE ENFERMAGEM DA UESPI}

\section{ASPECTOS EPIDEMIOLÓGICOS DA SÍFILIS CONGÊNITA NO ESTADO DO PIAUÍ}

Autores: Kellícia Rocha Arrais ${ }^{1}$, Jefferson Abraão Caetano Lira ${ }^{2}$, Rutielle Ferreira Silva², Julyanne dos Santos Nolêto ${ }^{2}$ Email: kelliciaarrais@gmail.com

Instituição: ${ }^{1}$ Universidade Estadual do Piauí (UESPI), Floriano - PI, Brasil. ${ }^{2}$ Universidade Federal do Piauí (UFPI), Teresina - PI, Brasil.

Eixo temático: Temas livres.

INTRODUÇÃO: A sífilis é uma Infecção Sexualmente Transmissível milenar e persistente. Quando acomete a gestante, pode provocar a sífilis congênita, responsável pela elevada morbimortalidade em conceptos. $\mathrm{O}$ efetivo controle da sífilis dependerá da qualidade da atenção à gestante e suas parcerias sexuais durante o pré-natal. OBJETIVO: Analisar o comportamento epidemiológico dos casos notificados de sífilis congênita no estado do Piauí. MÉTODOS: Trata-se de um estudo descritivo, retrospectivo, de abordagem quantitativa, em que foram analisados dados consolidados dos casos notificados de sífilis congênita no estado do Piaú, no período de 2014 a 2018. Realizou-se o levantamento epidemiológico através do Sistema de Informação de Agravos de Notificação (SINAN). Os dados foram analisados mediante estatística descritiva, utilizando frequência absoluta e percentual, por meio do Microsoft Excel 2016. RESULTADOS: No período em análise, foram diagnosticados 1.782 casos de sífilis congênita em neonatos, sendo 95,7\% até seis dias de vida. Destacou-se o ano de 2017 $(23,7 \%)$ com o maior número de casos. Em relação ao momento do diagnóstico, $44,7 \%$ tiveram o diagnóstico de sífilis durante o pré-natal, seguido do parto/curetagem (35,7\%). Quanto ao diagnóstico final dos casos, constatou-se que 93,1\% foram classificados como sífilis congênita recente. No tocante à escolaridade materna, 40,1\% tinham ensino fundamental incompleto e 85,2\% realizaram o pré-natal. Ressalta-se, ainda, que $61,2 \%$ dos parceiros não realizaram o tratamento. CONCLUSÃO: Torna-se imprescindível a ampliação do acesso ao diagnóstico precoce, assim como a sensibilização sobre a relevância do tratamento adequado à mulher e seu parceiro, a busca ativa, o seguimento e o acompanhamento sorológico até a comprovação da cura. À equipe multiprofissional compete a implementação de estratégias, como a sensibilização da população quanto aos riscos da prática sexual insegura e a importância do autocuidado, no intuito de minimizar o percentual de sífilis congênita no estado.

PALAVRAS-CHAVE: Vigilância Epidemiológica, Sífilis Congênita, Saúde Materno-Infantil. 


\section{ANAIS DA XVII SEMANA DE ENFERMAGEM DA UESPI}

\section{REFERÊNCIAS:}

BRASIL. Boletim Epidemiológico de Sífilis. Brasília: Ministério da Saúde, v.49, n.45, 2018.

WORLD HEALTH ORGANIZATION. Global Strategy for the Prevention and Control of Sexually transmitted infections: 2006-2015 breaking the chain of transmission. Geneva: WHO; 2007. 


\section{ANAIS DA XVII SEMANA DE ENFERMAGEM DA UESPI}

\section{ASSISTÊNCIA DE ENFERMAGEM À MULHER NO PUERPÉRIO}

Autores: Alice Vitória Reis Evelyn da Silva ${ }^{1}$, Laise Pereira da Silva Brito ${ }^{1}$, Mayara Rodrigues dos Santos ${ }^{1}$, Priscilla Souza Silva$^{1}$, Adriana da Silva Barros Andrade².E-mail:alicevitoriaevelyn21@gmail.com

Instituição: ${ }^{1}$ Universidade Estadual do Piauí - UESPI, Floriano-PI, Brasil, ${ }^{2}$ Especialista em Saúde Pública e da Família e em Docência do Ensino Superior; Floriano-PI, Brasil.

Eixo Temático: Temas Livres

INTRODUÇÃO: O puerpério é a etapa que se inicia logo após o parto com a supressão da placenta e termina quando o corpo consegue retornar o quanto antes ao estado anterior à gestação. A assistência à mulher no pós-parto e nas primeiras semanas após o parto é indispensável para a saúde materna e tornase essencial a assistência de enfermagem qualificada, sendo de fundamental importância a prevenção de complicações, o conforto emocional e físico. As alterações que se iniciam no puerpério, com a finalidade de restabelecer o organismo da puérpera a situação não gravídica, ocorrem não somente nos aspectos endócrinos e genital, mas como um todo. Dessa forma, à mulher no seu período puerperal deve ser vista como um ser integral. OBJETIVO: Identificar a importância da assistência de enfermagem à mulher no período puerperal. MÉTODO: O estudo em questão trata-se de uma revisão de literatura do tipo exploratória e com abordagem qualitativa. Os dados foram coletados nas bases de dados LILACS, SCIELO, BVS e BIREME, e no site de busca GOOGLE ACADÊMICO, através dos descritores: “Assistência de enfermagem no puerpério", "Período pós-parto" e "Enfermagem obstétrica". Em seguida foi feita a leitura sistemática dos artigos verificando-se a adequação ao objetivo proposto, com limite temporal de 2010 a 2019. Ao todo foram baixados 24 artigos, e após a leitura dos resumos foram selecionados 15 artigos para compor essa pesquisa. O estudo foi realizado no mês de abril de 2019 . RESULTADOS: O período puerperal é marcado por modificações locais e decorrentes da gravidez e do parto. Nesse momento é comum as mulheres sentirem-se vulneráveis perante a insegurança, dúvidas e ansiedade que permeiam tanto o cuidado com o recém-nascido quanto os reajustes familiares necessários e a autocuidado. A observação e avaliação clínica deve ser rigorosa. Assim a assistência de enfermagem deve ter os seguintes cuidados: Orientar cuidados com a higiene pessoal; estimular a deambulação precoce; incentivar o aleitamento materno; observar quantidade, aspecto dos lóquios; orientar a limpeza da incisão cirúrgica com água e sabão; orientar a abstinência sexual durante $45^{\circ}$ dias; agendar consulta médica de retorna em 1 semana; Orientar os cuidados com RN; promover vínculo mãe-bebe-pai. CONCLUSÃO: O puerpério é um momento no qual a mulher passa por diversas mudanças e necessita de considerável apoio tornando-se essenciais os cuidados de enfermagem capacitados que tenha como 


\section{ANAIS DA XVII SEMANA DE ENFERMAGEM DA UESPI}

base, prevenção de complicações, conforto físico e emocional e educação em saúde.

PALAVRAS-CHAVE: Enfermagem obstétrica; Período Pós-parto; Assistência de Enfermagem.

\section{REFERENCIAS}

Andrade RD; Santos JS; Maia MAC; Mello DF. Fatores relacionados à saúde da mulher no puerpério e repercussões na saúde da criança. Escola Anna Nery Revista de Enfermagem 19(1) Jan-Mar 2015.

Brasil. Ministério da Saúde. Política Nacional para Atenção Integral à Saúde da Mulher. Brasília: Ministério da Saúde. 2011.

Brasil. Ministério da Saúde. Manual dos Comitês de Mortalidade Materna. 3.ed. Brasília: Ministério da Saúde; 2007.

Oliveira JFB, Quirino GS, Rodrigues DP. Percepção das puérperas quanto aos cuidados prestados pela equipe de saúde no puerpério. Rev Rene. 2012;13(1):74-84.

Santos APV; Gomes GF. Assistência de enfermagem no puerpério. Revista Enfermagem Contemporânea. 2017 Outubrol;6(2):122-131.

Silva EC, Pereira ES, Santos WN dos et al. Puerpério e assistência de enfermagem: percepção das mulheres. Rev enferm UFPE online. Recife, 11(Supl.7):2826-33, julho 2017. 


\section{CONHECIMENTO DAS MÃES DE RECÉM NASCIDOS SUBMETIDOS A FOTOTERAPIA: REVISÃO DE LITERATURA}

Elusiany Sousa da Silva ${ }^{1}$, Arturgesina Martins Vasconcelos Lima ${ }^{1}$, Maraisa Piauilino de Lima ${ }^{1}$, Suzana Honória de Sousa ${ }^{1}$ Sueli de Sousa Estrela Araújo ${ }^{1}$, Adriana da Silva Barros Andrade'1. E-mail: elusiany13@gmail.com

${ }^{1}$ Universidade Estadual do Piauí - UESPI, Floriano-PI, Brasil

Eixo Temático: Temas Livres

INTRODUÇÃO: A fototerapia é o tratamento inicial utilizado para a icterícia, esse tratamento consiste em deixar a criança exposta à fonte de luz durante horas ou dias, os neonatos ficam em berço, apenas com fralda ou despidos e com venda nos olhos, submetidos à luz que sai de lâmpadas fluorescentes ou de LED. A luz neste tratamento tem a função de converter a bilirrubina, impregnada na pele e mucosas, em outra substância capaz de ser excretada pelo organismo do neonato, prevenindo desta forma a complicação mais grave OBJETIVO: Avaliar o conhecimento das mães de recém-nascidos submetidos a tratamento fototerápico. MÉTODOS: O estudo trata-se de uma revisão de literatura exploratória e descritiva, e de abordagem qualitativa na qual foi utilizada uma consulta sistemática nas bases de dados Scientific Eletronic Library Online (SciELO) e Biblioteca Virtual em Saúde (BVS) e no site do GOOGLE ACADÊMICO. Para a busca foram utilizados os descritores: Icterícia, Fototerapia, Bilirrubina Neonatal. Foram utilizados como critérios de inclusão: base de dados nacionais; idioma português; entre os períodos de 2010 a 2017; e logo após encontradas 20 publicações excluindo-se os artigos repetidos e que não atendiam a temática, dos quais restaram 12 artigos que contemplaram aos critérios definidos. A presente pesquisa foi realizada nos meses de março a abril de 2019. RESULTADOS: Pesquisas apontaram que o tratamento de fototerapia, além de interromper o vínculo direto entre mãe-bebê, é um tratamento que requer cuidados exclusivos e orientações específicas para quem cuida e principalmente às mães que desempenha lugar relevante de ajuda no cuidado com o seu filho. A experiência da mãe ao presenciar um filho sob uso de fototerapia é um momento doloroso, pois durante o tratamento diversas dificuldades e sentimentos podem surgir, aceitação da permanência prolongada do bebê no leito sob a ação da luz, ansiedade, insegurança, dúvidas, e falta de informação sobe o tratamento. Com isso apesar da situação vivenciada, as mães, quando são orientadas acerca da patologia e do tratamento, aceitam e até colaboram com o cuidado de enfermagem ao neonato sob fototerapia CONCLUSÃO: Portanto o apoio da equipe de saúde é fundamental através de esclarecimentos sobre o quadro clínico do recém-nascido e o cuidado prestado, com o intuito de fornecer informações e clarificar as dúvidas, assim a equipe multiprofissional será capaz de elaborar metas educativas que visem uma assistência humanizada ao binômio mãe e filho e a aceitação das mães e participação ativa durante o tratamento.

PALAVRAS CHAVES: Icterícia, Fototerapia, Bilirrubina Neonatal 


\section{REFERÊNCIAS}

ALMEIDA, M. F. B.; NADER, P. J. H.; DRAQUE, C.M. Icterícia neonatal. In: LOPEZ, F. A.; CAMPOSJÚNIOR, D.. Tratado de Pediatria. São Paulo:Manole, 2010. p. 1515-1526.

ARAÚJO, L.A.; REIS, A.T. Enfermagem na prática materno-neonatal. Guanabara Koogan: Rio de Janeiro, p.253, 2012.

CASTRO, Poliana da Silva; SILVA, Sérlia Maria de Souza; LINHARES, Thaís Regina Carvalho; SOUSA, Alcineide Mendes. O conhecimento das mães de recém-nascidos com icterícia neonatal sobre o tratamento fototerápico. Revista. Interdiciplinar NOVAFAPI, Teresina. v.5, n.1, p.16-20, Jan-FevMar.2012.

DURÁN M, GARCIA JA, SÁNCHEZ A. Efetividade da fototerapia na hiperbilirrubinemia neonatal. Enfermería Universitaria, 2015;12(1):41-45.

FERNANDES, J.I.S.et al. Desafios maternos frente à fototerapia neonatal: estudo descritivo. Online Brazilian Journal Nursing, Rio de Janeiro. 2016 v.15, n.2, p. 188-95.jun. Disponível em:<lt;http://www.objnursing.uff.br/index.php/nursing/article/view/5348/html_2>gt;Acesso em: 22.maio.19.

HOCKENBERRY, Marlyn J.; WILSON, David. WONG - Fundamentos de enfermagem pediátrica. Elsevier: Rio de Janeiro, p. 281, 2011.

INSTITUTO BRASILEIRO DE GEOGRAFIA E ESTATÍSTICA (IBGE). Sinopse do Censo Demográfico 2016 Piauí. Disponível em: <lt;http://www.censo2010.ibge.gov.br/sinopse/index.php?dados=26\&amp;uf=22.>. Acesso em: 28.out. 2018.

MENEZES, Priscilla Martins Araújo; VASCONCELOS, Maria Gorete Lucena. Tratamento fototerápico: repercussão do conhecimento e atitude das mães no cuidado ao filho. - Recife: O autor, 2012. 


\section{ANAIS DA XVII SEMANA DE ENFERMAGEM DA UESPI}

\section{EDUCAÇÃO EM SAÚDE SOBRE ALEITAMENTO MATERNO EM UMA MATERNIDADE REFERÊNCIA DO PIAUÍ: UM RELATO DE EXPERIÊNCIA}

Ana Christina de Sousa Baldoino ${ }^{1}$, Nanielle Silva Barbosa ${ }^{2}$, Kauan Gustavo de Carvalho², Ana Caroliny de Barros Lima ${ }^{2}$, Priscilla Souza Silva ${ }^{1}$, Ananda Carolina Barbosa da Silva². E-mail: christinabaldoino@hotmail.com

Instituição: ${ }^{1}$ Universidade Estadual do Piauí, Floriano - PI, Brasil, ${ }^{2}$ Universidade Estadual do Piauí, Teresina - PI, Brasil.

Eixo temático: Experiências acadêmicas na promoção da saúde.

INTRODUÇÃO: A prática do aleitamento materno tem sido defendida e apoiada no mundo inteiro como a melhor forma de nutrição, sendo fundamental para a proteção e desenvolvimento do recém-nascido. Exercendo assim, além das funções nutricionais, um importante papel no vínculo do binômio mãe-filho. OBJETIVO: Relatar a experiência de acadêmicos de enfermagem em uma atividade de educação em saúde sobre Aleitamento Materno. MÉTODO: Trata-se de um estudo descritivo do tipo relato de experiência, vivenciados por acadêmicos da Universidade Estadual do Piauí, sobre uma atividade voltada para as mães que estavam acompanhando os filhos no processo de cuidados no contexto hospitalar, realizada no mês de março, na Maternidade Dona Evangelina Rosa (MDER), Teresina, Piauí, tendo como alvo principal as mães que utilizavam os serviços do Método Canguru e da Unidade de Terapia Intensiva Neonatal (UTIN). Os pontos discutidos foram: A importância do aleitamento materno exclusivo, os benefícios do aleitamento materno para a mãe e o bebê, manuseio e doação do leite humano, com destaque para o consumo do seu filho (a). Após a abordagem teórica sobre os pontos discutidos, realizamos encenação teatral, apresentação de uma paródia com a temática, finalizando com distribuições de brindes. RESULTADOS: Contamos com um público de maioria mães e os demais eram profissionais da instituição. Ambos participaram de forma ativa em relação as discussões, onde os mesmos compartilharam experiências, dúvidas e medos acerca da temática, deixando claro o interesse as orientações relatadas. CONCLUSÃO: As atividades educativas é uma grande ferramenta no que diz respeito as ações de promoção a saúde, pois permite que desde a academia possamos entender a importância de se trabalhar temáticas diretamente com o público, acerca das necessidades dos mesmos. Podemos observar ainda que o contexto trabalhado proporciona medo, insegurança e sentimento de impotência as mulheres, mostrando que é de suma importância esse tipo de atividade, ressaltando o papel do profissional de enfermagem diante deste tipo de trabalho, já que o mesmo é o responsável pela a capacitação do indivíduo e promoção à saúde.

PALAVRAS-CHAVE: Aleitamento Materno, Educação em Saúde, Enfermagem. 


\section{ANAIS DA XVII SEMANA DE ENFERMAGEM DA UESPI}

\section{REFERÊNCIAS}

MARTINS, M. Z.; SANTANA, L. S. Benefícios da amamentação para saúde materna. Interfaces Científicas-Saúde e Ambiente, v. 1, n. 3, p. 87-97, 2013.

MENEZES, C. B.; SOARES, D. J. Benefícios do aleitamento materno exclusivo até os seis meses de vida.

em:\&lt;http://www.repositorio.unilab.edu.br:8080/jspui/handle/123456789/696\&gt;. Acesso em: 08 de mar. de 2019.

NUNES, L. M. Importância do aleitamento materno na atualidade. Boletim científico de pediatria. Porto Alegre. Vol. 4, n. 3 (dez. 2015), p. 55-58, 2015.

TOMA, T. S.; REA, M. F. Benefícios da amamentação para a saúde da mulher e da criança: um ensaio sobre as evidências. Cadernos de Saúde Pública, v. 24, p. s235-s246, 2008.

VIANA, R. M. S.; CASSINO, L. Aleitamento materno: fortalecedor do vínculo afetivo entre mãe e filho. Revista Brasileira de Ciências da Vida, v. 5, n. 2, 2017. 


\section{ANAIS DA XVII SEMANA DE ENFERMAGEM DA UESPI}

EFETIVIDADE DA PAPAÍNA NO TRATAMENTO DE FERIDAS: REVISÃO INTEGRATIVA

Autores: Kamilla Rocha Arrais ${ }^{1}$, Kellícia Rocha Arrais ${ }^{1}$, Karolay Sousa Silva ${ }^{1}$, Andréa Pereira da Silva ${ }^{1}$. E-mail: kamillarocha1658@gmail.com

Instituição: ${ }^{1}$ Universidade Estadual do Piauí-UESPI, Floriano-PI, Brasil.

Eixo temático: Temas livres.

INTRODUÇÃO: As feridas são consideradas um problema de saúde pública relevante devido a elevada prevalência e seu impacto na qualidade de vida do paciente. O tratamento envolve a utilização de algumas substâncias, dentre estas, destaca-se a papaína que consiste em uma enzima proteolítica derivada do látex do mamoeiro Carica papaya que causa a proteólise, degradação do tecido desvitalizado e/ou necrosado, sem alterar o tecido sadio. OBJETIVO: Analisar as evidências científicas disponíveis acerca da efetividade da papaína no processo de reparo de feridas. MÉTODO: Trata-se de uma revisão integrativa da literatura, realizada nas bases de dados LILACS e BDENF, utilizando como descritores, os termos: Papaína, Cicatrização e Cuidados de Enfermagem, com cruzamentos e conduzida pela seguinte questão norteadora: Quais as evidências científicas a respeito da efetividade da papaína no processo de cicatrização de feridas? A busca foi realizada em abril de 2019 e envolveu os estudos que atenderam aos seguintes critérios de inclusão: artigos relacionados à temática, disponível na íntegra, e publicados no período de 2014 a 2019, sendo encontrados 31 artigos. Após aplicação dos critérios de inclusão foram selecionados 8 estudos para análise e síntese. RESULTADOS: Houve variedade nos tipos de apresentação do produto: pó, gel, creme, soluções e spray, e concentrações: $2 \%$ a $10 \%$, demonstrando o desenvolvimento das tecnologias de cuidado voltadas à temática. Quanto ao uso da papaína observou-se que o gel de papaína a $2 \%$ e a $4 \%$ mostrou-se ser efetivo na redução do tecido de esfacelo e do edema, evolução positiva na profundidade das feridas, e quando da presença de exsudado purulento e/ou de infecções, as concentrações devem variar de $4 \%$ a $6 \%$, favorecendo o processo de epitelização, constando-se a efetividade da papaína como desbridante e estimulante do processo de cicatrização total de feridas, embora haja relatos de ardência e dor. Além disso, uma das investigações evidenciou que apenas a papaína a $10 \%$ mostrou-se ter atividade antibacteriana e recomendada quando há tecido necrótico abundante. CONCLUSÃO: A papaína é utilizada em feridas de diversas etiologias e em todas as fases da cicatrização, sem contraindicações específicas, sendo efetiva e segura. A seleção das melhores opções de coberturas deve levar em consideração a efetividade e menor custo, nesse sentido, o enfermeiro desempenha um papel importante, na avaliação e tratamento da ferida e promoção da qualidade de vida dos pacientes. Ademais, destaca-se a necessidade de pesquisas com maior rigor metodológico, que proporcionem evidências fortes do seu uso e recomendação.

PALAVRAS-CHAVE: Papaína, Cicatrização, Cuidados de Enfermagem. 


\section{ANAIS DA XVII SEMANA DE ENFERMAGEM DA UESPI}

\section{REFERÊECIAS:}

BRITO, Junior L.; FERREIRA, P. Cicatrização de feridas contaminadas tratadas com papaína. Medicina (Ribeirão Preto. Online), 2015;48(2): 168-74. Disponível em: http://www.revistas.usp.br/rmrp/article/view/99751. Acesso em: 15 abril 2019.

CABRAL, Jennifer Ferreira Figueiredo et al. Potencial da papaína em relação ao seu efeito na cicatrização de feridas crônicas: revisão integrativa. Revista Tendências da Enfermagem Profissional, Fortaleza, v.9, n.3, 2017. Disponível em: \&lt;http://www.coren-ce.org.br/wpcontent/uploads/2019/02/POTENCIAL-DA-PAPA\%C3\%8DNA-EM-RELA\%C3\%87\%C3\%83O-AOSEU-EFEITO-NA-CICATRIZA\%C3\%87\%C3\%83O.pdf\&gt;. Acesso em: 15 abril 2019.

RODRIGUES, A. L. S.; OLIVEIRA, B. G. R. B., et al. Efetividade do gel de papaína no tratamento de úlceras venosas: ensaio clínico randomizado. Revista Latino-Americana de Enfermagem. 2015;23(3):458-65. Disponível em: \&lt;DOI: http://dx.doi.org/10.1590/0104-1169.0381.2576\&gt;. Acesso em: 15 abril 2019.

RIBEIRO, Andréa Pinto Leite et al. Efetividade Dos Géis De Papaína A 2\% E 4\% Na Cicatrização De Úlceras Venosas. Revista da Escola de Enfermagem da USP, São Paulo, v.49, n. 3, p. 394-400, jun. 2015. Disponível em: \&lt;http://www.scielo.br/scielo.php?script=sci_arttext\&amp;pid=S008062342015000300394\&amp;lng=en\&amp;nrm=iso\&gt;. Acesso em: 15 abril 2019.

SILVA, Ana Catarina de Oliveira et al. As principais coberturas utilizadas pelo enfermeiro. Revista Uningá,v.53,n.2,jan.2018.Disponível

em:\&lt;http://revista.uninga.br/index.php/uninga/article/view/1426\&gt;. Acesso em: 15 abril 2019.

SOUZA, Maria Cristina Almeida de et al. Úlcera crônica tratada com gel de papaína $10 \%$ na Estratégia Saúde da Família: relato de experiência. Revista Brasileira de Medicina de Família e Comunidade, Rio de Janeiro, $2017 \quad$ Jan-Dez; $\quad 12(39): 1-8 . \quad$ Disponível em:\&lt;http://dx.doi.org/10.5712/rbmfc12(39)1355\&gt;. Acesso em: 15 abril 2019. 


\section{ANAIS DA XVII SEMANA DE ENFERMAGEM DA UESPI}

\section{FATORES DE RISCO ASSOCIADOS À SÍNDROME DE HELLP NA GESTAÇÃO: UMA REVISÃO INTEGRATIVA}

Autores: Iara Maria Lima da Silva ${ }^{1}$, Sandy Soares Sousa ${ }^{1}$, Yanneck Barbosa Silva ${ }^{1}$, Marianna Soares Cardoso ${ }^{2}$, Andréa Pereira da Silva1. E-mail: iara-raiure01@ hotmail.com

Instituição: ${ }^{1}$ Universidade Estadual do Piauí - UESPI, Floriano - PI, Brasil, ${ }^{2}$ Universidade Estadual do Piauí - UESPI, Teresina - PI, Brasil.

Eixo temático: Temas Livres.

INTRODUÇÃO: A Síndrome HELLP caracteriza-se pela hemólise, elevação das enzimas hepáticas e plaquetopenia durante a gestação. Consiste em uma das principais complicações de hipertensão arterial na gravidez e apresenta elevada prevalência de mortalidade materno infantil. A identificação dos fatores predisponentes ao desenvolvimento da Síndrome é relevante e oportuna para determinar o risco gestacional e realizar o manejo clínico adequado. OBJETIVO: Avaliar as evidências disponíveis na literatura sobre os fatores de risco relacionados à síndrome de HELLP na gestação, no período entre janeiro de 2006 a maio de 2019. MÉTODO: Trata-se de uma revisão integrativa da literatura, realizada nas seguintes bases de dados: LILACS, SCIELO, MEDLINE e BDENF, no período de abril a maio de 2019, conduzida pela seguinte questão norteadora: quais os fatores de risco associados à síndrome de HELLP na gestação? Utilizou-se os descritores cadastrados no DeCS, com a combinação do operador boleando AND, no seguinte esquema: HELLP Síndrome and Fatores de risco and Pré-eclâmpsia, foram encontrados 190 artigos. Após a aplicação dos critérios de inclusão e exclusão, obteve-se uma amostra final com 6 artigos. RESULTADOS: Os estudos encontrados definiram como fatores de risco para o desenvolvimento da síndrome de HELLP na gestação, mulheres que tenham tido alguma alteração hipertensiva na gestação, eclampsia/pré-eclâmpsia, idade maior que 25 anos, cor branca e multíparas. CONCLUSÃO: A identificação prévia dos fatores de risco relacionados ao aparecimento da Síndrome HELLP é necessária para adoção de medidas que assegurem a saúde da gestante e do feto. Além disso, observou-se uma grande dificuldade em encontrar estudos sobre os fatores de riscos que podem motivar o surgimento dessa síndrome na gestação, os trabalhos encontrados basicamente são firmados em registros de estudo de casos.

PALAVRAS-CHAVE: Síndrome de HELlP, Fatores de risco, Pré-eclâmpsia. 


\section{ANAIS DA XVII SEMANA DE ENFERMAGEM DA UESPI}

\section{REFERÊNCIAS:}

CARO M., José; ANWANDTER SCH., Carlos; SCHAFFELD P., Soledad; VEGA G., Fernando; LÓPEZS., Carolina; JARA P., Jacqueline. Síndrome HELLP: experiencia del Hospital Regional de Puerto Montt,2000-2006. Rev. chil. obstet. ginecol; 73(5): 318-324, 2008.

COELHO,Bernardo Cardoso Pinto; BRITO, Bruno Oliveira de Figueiredo; BRAGA,Cecília Alcantara; GARCIA, Eduardo Carvalho; BRAGA, Felipe Alcantara; SOUZA, Filipe Caetano Righi de; SEABRA, Liz Custódio Souza; VIEIRA, Mônica De Paoli Bennaton; LEITE, Henrique Vitor Leite. Síndrome HELLP:uma breve revisão. Rev Med Minas Gerais 2009; 19(2 Supl 3): S107-S111.

KATZ, Leila; AMORIN, Melania Maria Ramos de; MIRANDA, Giselly Veríssimo; SILVA, João Luiz Pinto e. Perfil clínico, laboratorial e complicações de pacientes com síndrome HELLP admitidas em uma unidade de terapia intensiva obstétrica. Rev. Bras. Ginecol. Obstet. [online]. 2008, vol.30, n.2, pp.8086.ISSN 0100-7203.

MIRANDA, Francine Krassota; KLEMANN, Douglas; CASTRO, Juceli Aparecida Amaral de; SOUZA, Silvia Jaqueline Pereira de; WEIGERT, Simone Planca; PIEMONT, Mariana da Rocha. Atuação da Enfermagem na síndrome de hellp - uma revisão de literatura. Revista Gestão \&amp; Saúde, v. 15, n. 1 , p. $39-45,2016$.

MENDES, Karina Dal Sasso; SILVEIRA, Renata Cristina de Campos Pereira; GALVÃO, Cristina Maria. Revisão integrativa: método de pesquisa para a incorporação de evidências na saúde e na enfermagem.Texto contexto - enferm., Florianópolis, v. 17, n. 4, Dec. 2008. Disponível em\&lt; http://dx.doi.org/10.1590/S0104-07072008000400018\&gt;. Acesso em: 26 abr. 2019.

OLIVEIRA, Maria Ivoneide Veríssimo de; VASCONCELOS, Simone Gonçalves. Puérperas com síndrome de Hellp: análise baseada nos aspectos obstétricos. Rev. RENE. Fortaleza. v. 7, n. 2, p. 74-80, mai./ago.2006.

OLIVEIRA, Roberto Santos de; MATOS, Ilma Cristina de; SILVA, Tainá Bonfim Pereira da; AZEVEDO, Neusa Maria de; ANDRADE, Marilda; DO ESPIRITO SANTO, Fatima Helena. Síndrome Hellp: estudo de revisão para o cuidado de enfermagem. Rev. Enferm. Glog. V. 11. N. 28. Oct. 2012. ISSN 1695-6141.

RIBEIRO, José Francisco; SOARES, Maria do Socorro de Almeida Chaves; RODRIGUES, Cleidiomar Oliveira; BEZERRA, Vanessa Oliveira Rodrigues; ARAÚJO, Kleiton Richard da Silva. Perfil sociodemografico e clínico de mulheres com síndrome HELLP. Rev. enferm. UFSM;6(4):569-577, out.dez. 2016.

RIBEIRO, José Francisco; MELO, Simone Santos e Silva; SILVA, Candida Costa; GUIMARÃES, SimoneVieira Carvalho; SANTOS, Tatiana Maria Melo Guimarães dos. Síndrome HELLP: caracterizaçãoobstétrica e modalidade de tratamento. Rev. enferm. UFPE on line;11(supl.3):1343-1348, mar.2017. 


\section{ANAIS DA XVII SEMANA DE ENFERMAGEM DA UESPI}

\section{MOTIVOS DA PROCURA AO CENTRO DE TESTAGEM E ACONSELHAMENTO DO MUNICÍPIO DE FLORIANO - PI}

Autores: Laise Pereira da Silva Brito ${ }^{1}$, Fabiano de Araujo Silva ${ }^{2}$, Maria Luzinete Rodrigues da Silva ${ }^{1}$, Mayara Rodrigues dos Santos $^{1}$, Wesley Romário Dias Martins ${ }^{2}$, Andréa Pereira da Silva1․ E-mail: laisepsbrito@gmail.com

Instituição: ${ }^{1}$ Universidade Estadual do Piauí, Floriano-PI, Brasil. ${ }^{2}$ Faculdade Única de Ipatinga, Ipatinga-MG, Brasil.

Eixo temático: Temas Livres

INTRODUÇÃO: A terapia antirretroviral propiciou uma melhoria no estado imunológico das pessoas vivendo com o Vírus da Imunodeficiência Humana (HIV), reduções na morbidade e mortalidade pela Síndrome da Imunodeficiência Humana (AIDS), o que melhorou significativamente a qualidade de vida das pessoas com HIV/AIDS. No entanto, a prevalência casos novos da infecção pelo HIV, na população adulta é crescente, devido os comportamentos sexuais de risco, que é entendido como o não uso do preservativo nas relações sexuais, múltiplos parceiros sexuais, o início precoce das relações sexuais e o uso de substâncias psicoativas durante as relações sexuais. OBJETIVO: Descrever os motivos de procura e realização do teste rápido (TR) anti-HIV realizado no Centro de Testagem e Aconselhamento (CTA) do município de Floriano-PI em 2017. METODOLOGIA: Pesquisa do tipo descritiva e documental, com abordagem quantitativa, realizada no CTA do município de Floriano-PI nos meses de março e abril de 2018, com base na análise de 33 formulários de identificação dos pacientes com diagnóstico positivo para o vírus HIV, no ano de 2017. A pesquisa foi submetida à apreciação e aprovada pelo Comitê de Ética e Pesquisa (CEP), da Universidade Estadual do Piauí - UESPI, por meio do Certificado de Apresentação para Apreciação Ética (CAAE) no 84179318.6.0000.5209. Durante a realização da pesquisa foi preservado todos os aspectos éticos preconizados pelas Resoluções 466/12 e 510/16 do Conselho Nacional de Saúde (CNS/MS), sobre a pesquisa envolvendo seres humanos. RESULTADOS: Em relação aos motivos da procura ao serviço de saúde oferecido pelo CTA do município, constatou-se que dentre os indivíduos estudados, 10 (30,3\%) realizaram o TR anti-HIV como meio de prevenção, seguido de $07(21,2 \%)$ casos por exposição a situação de risco, exame pré-natal e por outros motivos 06 (18,2\%), encaminhamento de serviço de saúde $03(9,1 \%)$ e conferir resultado anterior com $01(3 \%)$ caso. No que diz respeito o tipo de exposição ao vírus, à pesquisa mostrou que $26(78,8 \%)$ casos de infecção pelo vírus HIV se deram por meio da relação sexual, 01 (3\%) por transfusão sanguínea e $06(18,2 \%)$ por outros meios. CONCLUSÃO: A maioria da população procurou o CTA para investigar de forma preventiva, bem como por exposição a eventos de riscos. Espera-se que os dados obtidos possam subsidiar futuras intervenções em saúde para prevenção das doenças sexualmente transmissíveis e contribuir na formulação e implementação de políticas preventivas em saúde.

PALAVRAS-CHAVE: Infecções sexualmente transmissíveis, vírus da imunodeficiência humana, testes imunológicos. 


\section{ANAIS DA XVII SEMANA DE ENFERMAGEM DA UESPI}

\section{REFERÊNCIAS:}

BRASIL, Ministério da Saúde. Boletim epidemiológico-Aids e IST. Brasília. 2018. Disponível em: http://www.aids.gov.br/pt-br/pub/2018/boletim-epidemiologico-hivaids-2018 . Acesso em: 06 mai. 2019 MARTINS, Wesley Romário Dias. Perfil epidemiológico dos pacientes com HIV notificados e acompanhados pelo centro de testagem e aconselhamento no município de Floriano-PI. Monografia (graduação). Floriano-PI, 2018. 73f. : il. 


\section{ANAIS DA XVII SEMANA DE ENFERMAGEM DA UESPI}

\section{ORIENTAÇÃO SEXUAL E VULNERABILIDADE AO VÍRUS DA IMUNODEFICIÊNCIA HUMANA}

Autores: Laise Pereira da Silva Brito ${ }^{1}$, Fabiano de Araujo Silva ${ }^{2}$, Maria Luzinete Rodrigues da Silva ${ }^{1}$, Mayara Rodrigues dos Santos $^{1}$, Wesley Romário Dias Martins ${ }^{2}$, Andréa Pereira da Silva ${ }^{1}$. E-mail: laisepsbrito@gmail.com

Instituição: ${ }^{1}$ Universidade Estadual do Piauí, Floriano-PI, Brasil. ${ }^{2}$ Faculdade Única de Ipatinga, Ipatinga-MG, Brasil.

Eixo temático: Temas livres

INTRODUÇÃO: A Síndrome da Imunodeficiência Humana (AIDS) consiste em um dos principais agravos sexualmente transmissíveis e ocorre em um estágio tardio da infecção pelo Vírus da Imunodeficiência Humana (HIV). O perfil epidemiológico da vulnerabilidade ao HIV tem relação direta com os aspectos individuais e coletivos relacionados à exposição vírus e ao adoecimento. OBJETIVO: Caracterizar os casos positivos de //HIV quanto a orientação sexual dos pacientes atendidos pelo Centro de Testagem e Aconselhamento (CTA), do município de Floriano-PI. MÉTODOS: Estudo descritivo e documental, com abordagem quantitativa, realizado no CTA do município de Floriano-PI, no período de março a abril de 2018, com base na análise de 33 formulários de identificação dos pacientes com diagnóstico positivo para o HIV no ano de 2017. A pesquisa foi submetida à apreciação e aprovada pelo Comitê de Ética e Pesquisa (CEP), da Universidade Estadual do Piauí - UESPI, por meio do Certificado de Apresentação para Apreciação Ética (CAAE) nº 84179318.6.0000.5209. Durante a realização da pesquisa foi preservado todos os aspectos éticos preconizados pelas Resoluções 466/12 e 510/16 do Conselho Nacional de Saúde (CNS/MS), sobre a pesquisa envolvendo seres humanos. RESULTADOS: Os indivíduos heterossexuais foram os mais acometidos pela infecção do vírus HIV, com 28 (85\%) casos, seguido dos homossexuais com 04 (12\%) e 01 (3\%) caso para indivíduo bissexual. Os dados da presente investigação corroboram com as notificações nacionais que destaca que grande parte dos indivíduos infectados pelo vírus HIV contraiu por meio de relações heterossexuais. CONCLUSÃO: A transmissão do HIV foi prevalente nas pessoas heterossexuais, evidenciando dessa forma, modificação no perfil epidemiológico uma vez que a principal via de transmissão passou a ser a heterossexual de homem para mulher ou vice e versa o que aumentou significativamente o número de heterossexuais portadores do vírus HIV.

PALAVRAS-CHAVE: Vírus da imunodeficiência humana, orientação sexual, epidemiologia nos serviços de saúde. 


\section{ANAIS DA XVII SEMANA DE ENFERMAGEM DA UESPI}

\section{REFERÊNCIAS:}

BRASIL, Ministério da Saúde. Boletim epidemiológico-Aids e IST. Brasília. 2018. Disponível em: http://www.aids.gov.br/pt-br/pub/2018/boletim-epidemiologico-hivaids-2018 . Acesso em: 06 mai. 2019

MARTINS, Wesley Romário Dias. Perfil epidemiológico dos pacientes com HIV notificados e acompanhados pelo centro de testagem e aconselhamento no município de Floriano-PI. Monografia (graduação). Floriano-PI, 2018. 73f. : il. 


\section{ANAIS DA XVII SEMANA DE ENFERMAGEM DA UESPI}

\section{ENFERMAGEM FRENTE AOS EFEITOS ADVERSOS DA QUIMIOTERAPIA: UMA REVISÃO INTEGRATIVA DA LITERATURA}

Luan Wesley Marques Máximo ${ }^{1}$, Priscilla Souza Silva ${ }^{1}$, Ananda Carolina Barbosa da Silva ${ }^{2}$, Ana Caroliny de Barros Lima ${ }^{2}$, Kauan Gustavo de Carvalho², Nanielle Silva Barbosa ${ }^{2}$. E-mail: luanwesleymarque @ gmail.com

Instituição: ${ }^{1}$ Universidade Estadual do Piauí, Floriano - PI, Brasil, ${ }^{2}$ Universidade Estadual do Piauí, Teresina - PI, Brasil.

Eixo temático: Tema livre

INTRODUÇÃO: O câncer é considerado uma patologia crônico-degenerativa além de um problema de saúde pública crescente. Tanto o diagnóstico quanto o tratamento interferem na qualidade de vida dos pacientes. A enfermagem exerce papel fundamental no acompanhamento dos pacientes oncológicos, controlando as reações adversas, o que resulta na melhoria da qualidade de vida dos mesmos. OBJETIVOS: Discutir sobre as ações de enfermagem frente aos efeitos adversos decorrentes da quimioterapia. MÉTODOS: Estudo de revisão integrativa da literatura, realizado entre março e abril de 2019, nas bases eletrônicas de dados: Literatura Latino-Americana e do Caribe em Ciências da Saúde (LILACS), Cumulative Index to Nursing and Allied Health Literature (CINAHL) e Banco de Dados em Enfermagem (BDENF) utilizando os descritores: "quimioterapia", "efeitos adversos" e "cuidados de enfermagem". Foram identificados 256 estudos e após aplicação dos critérios de inclusão e exclusão ficaram 9 artigos para análise. Desses, 4 eram estudos de caso, 1 de análise retrospectiva dos dados e 1 apresentou abordagem qualitativa. O maior número de publicações, 5, compreenderam o ano de 2015. Destacaram-se as publicações nacionais e apenas 2 estudos internacionais. Não foram encontradas publicações realizadas no estado do Piauí. RESULTADOS: Observou-se que a quimioterapia é amplamente utilizada no tratamento do câncer, desta forma, pode se dividir os resultados em duas categorias: principais efeitos adversos da quimioterapia (mucosite, náuseas, vômitos, pancitopenia, alterações cardíacas, pneumonite, alopecia, efeitos psicológicos, etc.) e cuidados de enfermagem frente aos efeitos adversos da quimioterapia, onde descreve seu papel na identificação e tratamento das principais funções do organismo afetadas pelos fármacos. CONCLUSÃO: Apesar do tratamento quimioterápico ocasionar efeitos adversos comuns, deve-se considerar que a resposta de cada paciente é única, ou seja, tais manifestações podem não estar presentes com a mesma intensidade em todos os pacientes. A enfermagem tem papel fundamental ao incentivar e desenvolver as potencialidades dos pacientes e familiares, colaborando com ações voltadas para o enfrentamento dos problemas decorrentes desse tratamento e favorecendo sua continuação. Cabe destacar que as intervenções de enfermagem devem ser sistematizadas, baseadas em protocolos e adequadamente registradas.

PALAVRAS-CHAVE: Quimioterapia, Efeitos Adversos, Cuidados de Enfermagem. 


\section{ANAIS DA XVII SEMANA DE ENFERMAGEM DA UESPI}

\section{REFERÊNCIAS:}

BAITELO, Tamara Cristina; ALONSO REIS, Ana Paula; VALIM CÔRTES GRADIM, Clícia. A atuação da enfermagem na alopecia da mulher com câncer de mama: revisão integrativa. Journal of Nursing UFPE/Revista de Enfermagem UFPE, v. 9, n. 11, 2015.

CAVALER, Aline Warmling Warmling et al. Assistência de enfermagem frente aos efeitos colaterais em pacientes submetidos a quimioterapia. Revista Interdisciplinar de Estudos em Saúde, v. 6, n. 1, p. 200212, 2017.

CORPORAL, Composição. Influência da composição corporal sobre a qualidade de vida de pacientes com câncer. Revista Brasileira de Cancerologia, v. 61, n. 4, p. 351-357, 2015.

DA CRUZ, Fernanda Strapazzon; ROSSATO, Luciana Grazziotin. Cuidados com o paciente oncológico em tratamento quimioterápico: o conhecimento dos enfermeiros da Estratégia Saúde da Família. Revista Brasileira de Cancerologia, v. 61, n. 4, p. 335-341, 2015.

GUIMARÃES, Rita de Cássia Ribeiro et al. Ações de enfermagem frente às reações a quimioterápicos em pacientes oncológicos. Revista de Pesquisa Cuidado é Fundamental Online, v. 7, n. 2, p. 24402452, 2015. 


\section{ANAIS DA XVII SEMANA DE ENFERMAGEM DA UESPI}

\section{PERSISTÊNCIA DO ESTIGMA SOCIAL FRENTE AO ACOMETIDO PELA HANSENÍASE}

Autores: Matheus de Sousa ${ }^{1}$, Antonio Gabriel dos Santos Castro ${ }^{1}$, Misael Magalhães Santos Alves ${ }^{1}$, Jhussara Silva Alves ${ }^{1}$, Államy Danilo Moura e Silva ${ }^{1}$ E-mail: menesessousamatheus@gmail.com

Instituição: ${ }^{1}$ Universidade Estadual do Piauí, Floriano - PI, Brasil.

Eixo temático: Saúde Pública.

INTRODUÇÃO: A hanseníase ainda é um problema de saúde pública no Brasil, que aliada a um grande preconceito se torna muito mais devastadora. Mesmo considerada a doença mais antiga do mundo, ainda carece de muito mais conhecimento por parte da sociedade, que continua alimentando um grande e antigo estigma. No Brasil, além de lidar com as complicações físicas da doença, muitos dos acometidos da hanseníase também desenvolvem danos mentais, estes que surgem diretamente pelas alterações na vida social, profissional e sexual dos mesmos. OBJETIVO: Analisar a persistência do estigma social frente ao acometido pela hanseníase. METODOLOGIA: Trata-se de uma revisão integrativa de literatura, foram utilizadas as plataformas de pesquisa Biblioteca Virtual em Saúde (BVS), Banco de Dados em Enfermagem (BDENF) e Medical Literature Analysis and Retrieval System Online (MEDLINE), através de palavras controladas pelos Descritores em Ciências da Saúde (DeCS): hanseníase, preconceito e estigma. Obteve-se 40 artigos, sendo incluídos estudos disponíveis gratuitos, publicados entre 2013 até 2018, nos idiomas Português, Espanhol e Inglês. Excluíram-se os estudos duplicados e que não respondiam à questão norteadora. Após a seleção os estudos foram categorizados e analisados de forma descritiva, totalizando uma amostra final de 9 artigos. RESULTADOS: Com relação ao preconceito às pessoas com hanseníase, constatou-se que é frequente e marcante ainda nas últimas décadas, alimentado pelos mitos e pela falta de informação da doença para com a população. Evidenciou-se que os danos psicológicos causados pelo isolamento e descriminação ao acometido pela doença, muitas vezes ultrapassa os danos físicos, na maioria dos casos o paciente vê seus laços afetivos sendo rompidos pouco a pouco, sem nada poder fazer. Vida sexual, interação social, entre outras atividades corriqueiras humanas, passam a ser apenas fruto de um passado que o acometido pela hanseníase um dia viveu. Cabe destacar que o isolamento do paciente se dá não apenas ao âmbito social, mas também ao tratamento, desprovido de uma vivência normal e feliz, o paciente muitas vezes perde a vontade de viver e pode apresentar depressão. CONCLUSÃO: Conclui-se que são várias as complicações trazidas pelo preconceito e desinformação para com o acometido pela hanseníase, e que pesquisas acerca da temática são fundamentais para desmitificar e transformar a visão social acerca da doença.

Palavras-chave: Hanseníase, Preconceito, Estigma 


\section{ANAIS DA XVII SEMANA DE ENFERMAGEM DA UESPI}

\section{REFERÊNCIAS}

ALMEIDA, AIS, et al. Marcas do passado: Memórias e sentimentos de (ex) portadores de hanseníase residentes em um antigo "leprosário". Enferm. Foco, 2018.

DIAS, ACNS, et al. Vivência e sentimentos de mulheres portadoras de hanseníase. Revista de Enfermagem - REUOL, 2017.

PALMEIRA, IP; QUEIROZ, ABA; FERREIRA, MA. Marcas em si: vivenciando a dor do (auto) preconceito. REBEn: Revista Brasileira de Enfermagem, 2013.

PINHEIRO, MGC; SIMPSON, CA. Preconceito, estigma e exclusão social: trajetória de familiares influenciada pelo tratamento asilar da hanseníase. Rev. Enferm UERJ, Rio de janeiro, 2018.

SILVA, RCC; et al. Estigma e preconceito: realidade de portadores de hanseníase em unidades prisionais. Revista de Pesquisa Cuidado é Fundamental Online, 2014. 


\section{ANAIS DA XVII SEMANA DE ENFERMAGEM DA UESPI}

\section{REFLEXÃO DA FORMAÇÃO ACADÊMICA NO CUIDADO HUMANIZADO EM ENFERMAGEM: REVISÃO DE LITERATURA}

$\underline{\text { Sueli de Sousa Estrela Araújo }}{ }^{1}$, Arturgesina Martins Vasconcelos Lima ${ }^{1}$; Elusiany Sousa Silva ${ }^{1}$, Maraisa Piauilino de Lima $^{1}$, Suzana Honória de Sousa ${ }^{1}$, Mohema Duarte de Oliveira ${ }^{1}$. E-mail: suelyestrela@ hotmail.com

${ }^{1}$ Universidade Estadual do Piauí - UESPI, Floriano-PI, Brasil

Eixo temático: Boas Práticas de Enfermagem na Assistência, Ensino, Pesquisa e Gestão

INTRODUÇÃO: Práticas humanizadas são características do cuidado que requerem aperfeiçoamento e devem está voltada para o usuário com a construção, participação, responsabilização e autonomia dos profissionais de saúde durante a formação. OBJETIVO: Efetuar uma reflexão do desenvolvimento acadêmico na assistência humanizada em enfermagem. MÉTODOS: A pesquisa realizada baseou-se a partir de revisão de literatura, de caráter qualitativo. Os dados foram apanhados a partir de uma apreciação criteriosa de análise e leitura de artigos publicados na Biblioteca Virtual de Saúde (BVS). Dessa forma foram encontrados 204 artigos, destes foram selecionados 20 artigos, mas somente 4 se incluíram nos critérios de inclusão: artigos completos e que os sujeitos de estudo fossem acadêmicos ou egressos de enfermagem. Tal revisão realizou-se em maio de 2019, sendo constituída de artigos especializados.

RESULTADOS: Pesquisas apontaram que as instituições de ensino de cursos em saúde ainda não priorizam na formação dos estudantes sensibilizados com as necessidades da sociedade e cuja identidade seja carregada de conhecimento teórico da prática humanizada, baseado nos princípios de cidadania, respeito e justiça social. Em relação à ética no processo de saúde e formação humanizada do profissional de saúde, não se deve esquecer as disciplinas que visam o conhecimento das relações humanas, devendo ressaltar a ética humana e o respeito à dignidade. Estudos com egressos de enfermagem constatou que grande parte dos acadêmicos reafirma que o curso atuou significativamente para um cuidado humano através de técnicas que qualifiquem o exercício profissional efetivo. No processo de formação profissional, os integrantes têm o dever de vivenciar espaços que propiciem o aprendizado e os desafios de atuarem em equipe. Assim os acadêmicos devem ser vistos como um sujeito personagem do seu processo de ensino-aprendizagem, como alguém que executa algo, gerencia e cuida, para que a partir das vivências no cotidiano encontre sujeitos motivadores no processo de ensino aprendizagem, capazes de intervir na realidade, buscando novas soluções, motivando novas maneiras de cuidado. CONCLUSÃO: Este trabalho não tem como anseio encerrar em si mesmo a busca por recursos para o processo de humanização, mas cooperar, através da abordagem de trabalhos publicados a respeito do tema, com informações relevantes para estudantes de saúde. As modificações ocorridas no âmbito da grade curricular na graduação em Enfermagem têm seguido a transformação de referenciais da educação e das políticas de saúde em contexto mundial, assim direcionando para a necessidade de reestruturar a 
formação de futuros profissionais de enfermagem e capacitação de docentes.

PALAVRAS-CHAVE: Educação em Enfermagem, Humanização, Ensino.

\section{REFERENCIAS:}

GERMANO, Raimunda Medeiros. A pesquisa e os dilemas éticos do trabalho da Enfermagem. Rev. bras. enferm. [online]. 2013, vol.66, n.spe, pp. 76-79. ISSN 0034-7167.

FRANCISCO, A. M.; COSTA, M. C. G.; HAMAMOTO, C. G; HAFNER, M. L. M. B. Avaliação da formação de enfermeiros: o reflexo dos métodos de ensino-aprendizagem e pressupostos curriculares na prática profissional. Avaliação, Campinas; Sorocaba, SP, v. 21, n. 2, p. 479-502, jul. 2016.

CASATE, Juliana Cristina; CORRÊA, Adriana Katia. A humanização do cuidado na formação dos profissionais de saúde nos cursos de graduação. Rev Esc Enferm USP 2012; 46(1):219-26. 


\section{ANAIS DA XVII SEMANA DE ENFERMAGEM DA UESPI}

\section{TRABALHOS DA XVII SEMANA DE ENFERMAGEM DA UESPI PREMIADOS COM MENÇÃO HONROSA}




\section{ANAIS DA XVII SEMANA DE ENFERMAGEM DA UESPI}

\section{MODALIDADE COMUNICACÃO ORAL}

$1^{\circ}$ LUGAR - "DO ESTRESSE OCUPACIONAL AO SURGIMENTO DA SÍNDROME DE BURNOUT EM PROFISSIONAIS DE ENFERMAGEM: UMA REVISÃO INTEGRATIVA". Hernandes Flanklin Carvalho Oliveira, Magdiel da Costa Silva, Suzana Honória de Sousa, Raiane Araújo Brito, Jhussara Silva Alves, Evelyne Ellene Alves de Carvalho.

\section{$\underline{2}^{\circ}$ LUGAR - "DESENVOLVIMENTO E ANÁLISE FÍSICO - QUÍMICO DA PLANTA} CITRONELA COMO REPELENTE VEICULADO EM GEL CREME”. Aludy Karina de Carvalho Costa.

3 LUGAR - "DINÂMICA GRUPAL COMO ESTRATÉGIA TERAPÊUTICA EM UM CENTRO DE ATENÇÃO PSICOSSOCIAL". Priscilla Souza Silva, Ananda Carolina Barbosa da Silva, Ana Caroliny de Barros Soares Lima, Nanielle Silva Barbosa, Kauan Gustavo de Carvalho, Lorena Uchoa Portela Veloso.

\section{MODALIDADE PÔSTER}

$1^{\circ}$ LUGAR - "ASSISTÊNCIA DE ENFERMAGEM AO PACIENTE NO PÓS-OPERATÓRIO DE PROSTATECTOMIA: RELATO DE EXPERIÊNCIA". Arturgesina Martins Vasconcelos Lima, Suzana Honória de Sousa, Conceição de Maria Vasconcelos Alves, Sueli de Sousa Estrela Araújo, Elusiany Sousa da Silva, Maria Luzinete Rodrigues da Silva.

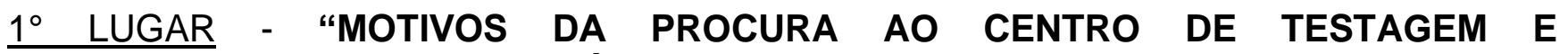
ACONSELHAMENTO DO MUNICÍPIO DE FLORIANO - PI". Laise Pereira da Silva Brito, Fabiano de Araujo Silva, Maria Luzinete Rodrigues da Silva, Mayara Rodrigues dos Santos, Wesley Romário Dias Martins, Andréa Pereira da Silva.

$1^{\circ}$ LUGAR - "ENFERMAGEM FRENTE AOS EFEITOS ADVERSOS DA QUIMIOTERAPIA: UMA REVISÃO INTEGRATIVA DA LITERATURA". Luan Wesley Marques Máximo, Priscilla Souza Silva, Ananda Carolina Barbosa da Silva, Ana Caroliny de Barros Lima, Kauan Gustavo de Carvalho, Nanielle Silva Barbosa.

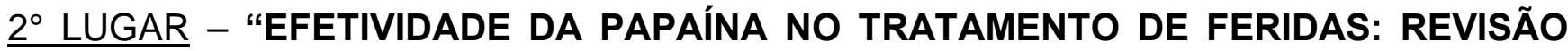
INTEGRATIVA". Kamilla Rocha Arrais, Kellícia Rocha Arrais, Karolay Sousa Silva, Andréa Pereira da Silva.

3० LUGAR - “ASSISTÊNCIA DE ENFERMAGEM À MULHER NO PUERPÉRIO”. Alice Vitória Reis Evelyn da Silva, Laise Pereira da Silva Brito, Mayara Rodrigues dos Santos, Priscilla Souza Silva, Adriana da Silva Barros Andrade. 


\section{ANAIS DA XVII SEMANA DE ENFERMAGEM DA UESPI}

\section{Todos os nossos sonhos}

podem-se realizar, se tivermos

a coragem de persegui-los.

\section{- Walt Disney}

\section{ACERVO Malsilomolas}

As publicações mais rápidas do país!

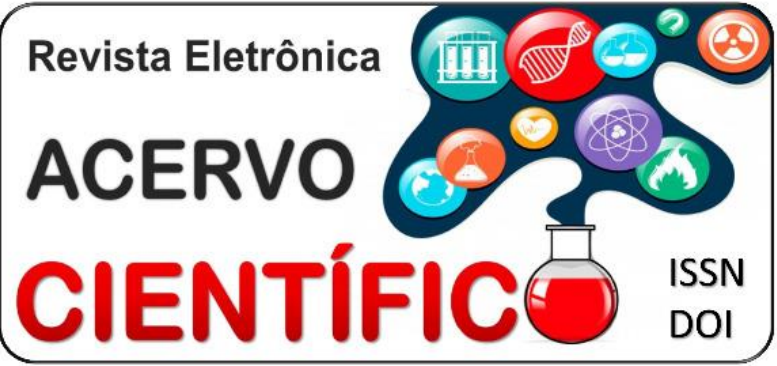

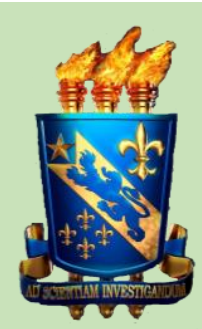

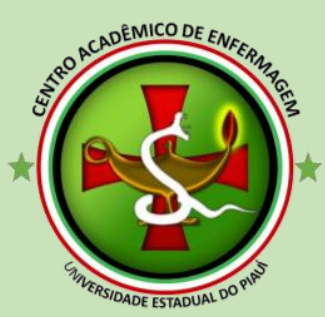

